\title{
„Gelobt sei der HerR, mein Fels ...!“ (Ps 144,1) Wirkung und Bedeutung von Psalm 18 (// 2 Samuel 22) im Nachfeld des Psalters ${ }^{1}$
}

\section{BEAT WEBER (THEOLOGISCHES SEMINAR BIENENBERG [LIESTAL] AND University of Pretoria)}

Im Gedenken an Frank-Lothar Hossfeld (19.VI.1942-2.XI.2015), den Psalmen- und Psalterforscher ${ }^{2}$

\begin{abstract}
In hermeneutischen Vorüberlegungen wird die Bedeutung des Psalters als Buch und entsprechend die Wahrnehmung der Psalmen in ihrer Abfolge (lectio continua) begründet. Der davidische Psalter enthält zudem einen Rezeptionsvektor „zurück“ zu den Geschichtserzählungen der Samuelbücher. Neben Angaben in den Psalmpräskripten ist die Doppelgestalt des königlich-davidischen Danklieds 2 Sam 22 // Ps 18 wesentlicher Bestandteil dieses Rezeptionsgefälles. Ergänzend zu Studien, die das textliche Vorfeld von Ps 18 untersuchten, widmet sich dieser Beitrag dessen Nachfeld (Ps 19-150). Dazu werden im Blick auf Ps 18 Wiederaufnahmen von Gattung (Königspsalmen) sowie von Begriffen und Motiven (Zuflucht, Rettung, Theophanie u. a.) erarbeitet. Solche finden sich vornehmlich im Nahkontext (Ps 19-21), in einigen (weisheitlichen) Psalmen im ersten Davidpsalter, am Ende von Teilbuch II und III (Ps 71-72; 89) sowie zu Beginn und gegen Schluss der Teilbücher IV-V (Ps 91; 94 und besonders 144). Im Buchfortlauf ist dabei eine
\end{abstract}

* Artikel eingereicht: 2015/12/02; akzeptiert: 2016/02/22. Beat Weber, „'Gelobt sei der HERR, mein Fels ...!' (Ps 144,1) Wirkung und Bedeutung von Psalm 18 (// 2 Samuel 22) im Nachfeld des Psalters,“ OTE 29/1 (2016): 195-220. DOI: http: // dx.doi.org/10.17159/2312-3621/2016/v29n1a12

1 Der vorliegende Beitrag steht im Zusammenhang mit dem Status des Verfassers als „Research Associate of the Department of Ancient Languages and Cultures at the University of Pretoria, Pretoria, South Africa." Ich danke Pfr. Dr. Edgar Kellenberger und Prof. Dr. Phil Botha für Hilfen, Hinweise und Korrekturlesungen.

2 Bei der Fertigstellung des Manuskripts traf aus Bonn die Nachricht vom Hinschied Frank-Lothar Hossfelds ein. Damit ist nach Erich Zenger auch der zweite des angesehenen „Kommentatoren-Tandems“ zu den Psalmen von uns gegangen. An der Bonner Fachtagung im Oktober 2012 referierte er zum Thema „Trägerkreise und Davidisierung“ und erwähnte dort die besondere Bedeutung, die der grosse Königspsalm 18 für die Davidisierung des Psalters habe. Es war dies meine letzte persönliche Begegnung mit ihm. Diese kleine Studie zum grossen Königpsalm und seiner Wirkung im Psalter sei darum dem bedeutenden Psalmenforscher gewidmet. 
196 Weber, „Gelobt sei der HERR, mein Fels ...!“ OTE 29/1 (2016): 195-220

Umgewichtung in Richtung Entmilitarisierung, Theologisierung und verstärkt betonter Frömmigkeit festzustellen.

In a preliminary hermeneutic deliberation, the meaning of the Psalter as a book and the importance of perceiving the individual psalms in sequence (lectio continua) is established. The Davidic Psalter furthermore contains a reception vector "back" to the historical narratives in the books of Samuel. In addition to details provided in the psalm headings, the duplicated transmission of the royal Davidic song of thanksgiving, 2 Sam 22 // Ps 18, forms an integral part of this reception connection. In addition to studies that have investigated the textual "prelude" of Ps 18, this article addresses the "postlude" (Ps 19-150). For this purpose, recurrences of Gattung (royal psalms) and of concepts and motifs (refuge, rescue, theophany, etc.) are worked out in view of Ps 18. These are found predominantly in the immediate context (Ps 19-21); in a number of (sapiential) psalms in the first Davidic Psalter; at the end of Books II and III (Ps 71-72; 89); and at the beginning and towards the end of Books IV-V (Ps 91; 94 and especially 144). In reading through the book, one finds a shift in emphasis towards demilitarization, theologizing and an increased stress on piety.

KEYWORDS: 2 Samuel 22; Psalm 18; Psalm 144; David; Book of Psalms; Psalter; Canon.

\section{A HERMENEUTISCHE VORBEMERKUNGEN}

\section{$1 \quad$ Zur Geltung des Psalters}

Die neuere Psalmenforschung, die heute global, aber mit besonderen Schwerpunkten in Kontinentaleuropa, ${ }^{3}$ Nordamerika und erfreulicherweise auch in Südafrika ${ }^{4}$ betrieben wird, hat sich auch als Psalter- bzw. Psalmenbuchforschung etabliert. Mit andern Worten: Neben dem Fokus auf die einzelnen Psalmen in ihren literarischen, historischen, traditionsgeschichtlichen, liturgischen und theologischen Settings (Poetik, Gattung, Vergleiche mit verwandten Texten des Alten Orients etc.) richtet sich der Blick vermehrt auch auf die Buchgestalt sowie textliche Verbindungen $\mathrm{zu}$ andern Bibel-

$3 \mathrm{Zu}$ erwähnen sind namentlich Forschende und Teams in Bonn, Linz, Rom und Tübingen, dazu in UK Susan Gillingham.

4 Innerhalb Südafrikas liegt der Schwerpunkt an der Universität Pretoria, wo an der Theologischen Fakultät Dirk Human jährlich zu „ProPsalms“-Konferenzen einlädt (Tagungsbände publiziert in der Serie LHBOTS) und wo an unserem Department of Ancient Languages and Cultures diverse Psalmenstudien publiziert wurden und werden und Kommentierungen der Psalmen in der Reihe HICOT (durch Phil Botha und Gert Prinsloo) vorgesehen sind. 
büchern. Dabei kommen in unterschiedlicher Weise und Mischung diachrone und synchrone Methodenzugänge zur Anwendung. ${ }^{5}$

Neben der (diachronen) Nachzeichnung der Genese des Psalters und der (synchronen) Erfassung ihres Gehalts ist ein für das Verständnis wesentliches, drittes „G“ in den Blick zu nehmen: die Geltung. Dieser Aspekt stellt in Rechnung, dass die Herausbildung, Formierung und Etablierung biblischer Schriften - wie immer man solche Prozesse geschichtlich ansetzt - mit Vorgängen der Autorisierung innerhalb den überliefernden jüdischen (und später christlichen) Glaubensgemeinschaften einherging. In diese Schriften fanden Überlieferungen (samt deren Auslegungen und Aktualisierungen) Eingang, die sich als „offenbarungsmächtig“ erwiesen (hatten): Sie sprachen über Gott (JHWH), liessen ihn sprechen und brachten ihn ,zu Geltung.“ Beim Psalmenbuch war dies insofern speziell, als sich damit eine Überlagerung der Kommunikationsrichtung verband: Die einzelnen Psalmen, mehrheitlich Gebete, also Wort an Gott, wurden durch die Einbindung in den Psalter zugleich Schriftwort und damit (auch) als Wort von/über Gott entgegen genommen. ${ }^{6}$ Die in den Schriften aus Qumran und im Neuen Testament greifbare „prophetische“ Verwendung von Psalmen ist Ausfluss dieser Verbindung von Autoritäts-Akkumulierung und Kommunikationsveränderung.

Der Geltungsanspruch und damit die Normativität von Büchern und ihren Texten ist mit den Instrumentarien der Sprach-, Literatur- und Geschichtswissenschaften - so unentbehrlich diese sind und bleiben - nicht hinreichend in den Blick zu bekommen. Es bedarf der Theologie, und die Bibelwissenschaft wird damit (auch) zur Theologie. Damit verbunden ist ein Phänomen, das wir mit dem Begriff „Kanon“ bezeichnen: Eine in Selektions-

5 Für einen knappen Überblick zur Psalmen- und Psalterforschung vgl. Beat Weber, „Die Psalmen: Persönliche Akzente zu Psalmen und Psalter sowie deren Erforschung," in »Wie ein Baum, eingepflanzt an Wasserrinnen " (Psalm 1,3): Beiträge zur Poesie und Theologie von Psalmen und Psalter in Wissenschaft und Kirche (von Beat Weber; hrsg. von Torsten Uhlig; ABG 41; Leipzig: Evangelische Verlagsanstalt, 2014), 18-29. Vgl. auch die von mir digital allgemein zugänglich gemachte Bibliographie zu Psalmen und Psalter (ab 1990) unter: Beat Weber, „BiblioPss1990+: Bibliography of Psalms and the Psalter since 1990 (Update II.2016),“ 192 [zitiert 1. März 2016]. Online: https://www.academia.edu /5910732 /BiblioPss1990_Bibliography_of_Psalms_and_the_Psalter_since_1990_Update_III.20 16 .

6 Vgl. dazu Beat Weber, „Die Psalmen als Wort zu Gott und als Wort von Gott: Über den Sondercharakter des Psalmenbuchs innerhalb der Heiligen Schrift,“ in »Wie ein Baum, eingepflanzt an Wasserrinnen " (Psalm 1,3): Beiträge zur Poesie und Theologie von Psalmen und Psalter in Wissenschaft und Kirche (von Beat Weber; hrsg. von Torsten Uhlig; ABG 41; Leipzig: Evangelische Verlagsanstalt, 2014), 458462; Beat Weber, Werkbuch Psalmen III. Theologie und Spiritualität des Psalters und seiner Psalmen (Stuttgart: Kohlhammer, 2010), 252-261. 
prozessen herausgebildete Vielheit von autoritativen Schriften (und Inhalten/Theologien) wird in einer Rezeptionsgemeinschaft als gültige Einheit (Makrotext) verstanden und gegenüber andern Schriften, denen nicht dieselbe Geltung zuerkannt wird, herausgehoben. Dieser gestaffelte Prozess der Kanonisierung des biblischen Schrifttums ist zwar sozio-historisch (teilweise) beschreibbar, aber die dahinter stehenden Triebkräfte und Motive sind nicht vollends einsehbar. Sie werden theologisch mit der Offenbarungs- und Wirkmächtigkeit Gottes in Zusammenhang gebracht.

Als für unseren Zusammenhang hier wesentlich ist festzuhalten, dass „Theologie“ und „Kanon“ nicht aufoktroyiert und damit von der Sache selbst ablösbare Interpretamente sind. Vielmehr sind sie in die Verschriftung als geschichtliches Geschehen immer schon ,hineinverwickelt“ - und dies weit früher, als sich der Begriff „Kanon“ in der christlichen Antike etabliert. ${ }^{7}$ Damit sind nun nicht nur die komplexen Prozesse von Entstehung, Autorisierung und Etablierung des Psalmenbuchs im Blick, sondern zugleich die Bezüge zu andern Bibelbüchern. ${ }^{8}$ Die Buch- und Bibelwerdung („Kanonizität“) des Psalters ist ohne das „Zusammenspiel“ (Intertextualität) mit anderem Schrifttum (und deren Autorität) nicht zu denken. Gerade der Psalter zeichnet sich durch eine hohe „Verweiskapazität“ zu anderen Bibelbüchern aus, so dass man von einer ,eingeschriebenen Sekundarität" sprechen darf. ${ }^{9}$ Diese, bereits in der Psalterouvertüre - insbesondere Ps 1 - greifbare „Andockung“ an (Schriften aus den Kanonteilen) Tora und Nebi'im ist ebenfalls mit Momenten der Autorisierung verbunden. ${ }^{10}$ Von den Buchverbindungen des Psalters greifen wir nachfolgend eine heraus; sie ist besonders signifikant.

7 Man mag die Herausbildung des alttestamentlichen Schrifttums in antik-jüdischer Zeit als ,proto-kanonisch“ bezeichnen.

8 Anzumerken ist, dass „Bücher“ erst später in der Gestalt von Kodices vorlagen. Bis in frühchristliche Zeit hinein ist von (Buch-)Rollen auszugehen. Damit ist auch gesagt, dass eine Konfiguration, insbesondere eine Sequenz von einzelnen biblischen Büchern - insofern sie nicht auf ein-und-derselben Rolle figurieren - anders zu denken ist, als wenn sämtliche Schriften in einem Kodex enthalten sind. Gleichwohl ist eine „Ordnung“ wahrscheinlich; dazu Timothy J. Stone, The Compilational History of the Megilloth: Canon, Contoured Intertextuality and Meaning in the Writings (FAT II/59; Tübingen: Mohr Siebeck, 2013), 79-117.

9 Vgl. Beat Weber, „Von der Psaltergenese zur Psaltertheologie: Der nächste Schritt der Psalterexegese?! Einige grundsätzliche Überlegungen zum Psalter als Buch und Kanonteil“", in »Wie ein Baum, eingepflanzt an Wasserrinnen «(Psalm 1,3): Beiträge zur Poesie und Theologie von Psalmen und Psalter in Wissenschaft und Kirche (von Beat Weber; hrsg. von Torsten Uhlig; ABG 41; Leipzig: Evangelische Verlagsanstalt, 2014), 458-462; Weber, Werkbuch Psalmen III, 68-70.

10 Vgl. dazu Beat Weber, „Der Beitrag von Psalm 1 zu einer, Theologie der Schrift,““ JETh 20 (2006): 83-113; Beat Weber, „Psalm 1 als Tor zur Tora JHWHs: Wie Ps 1 (und Ps 2) den Psalter an den Pentateuch anschliesst“", in »Wie ein Baum, 
Weber, „Gelobt sei der HERR, mein Fels ...!“ OTE 29/1 (2016): 195-220

\section{Zur Verbindung des Psalters mit den Samuelbüchern (David)}

Die Überlappung der Samuelbücher und des Psalters durch die weithin identischen poetischen Stücke 2 Sam 22,1-51 und Ps 18,1-51 darf als offensichtlichste und markanteste Verbindung gelten, die das Psalmenbuch mit einer anderen Schrift aufweist. Entsprechend des zuvor Ausgeführten interessieren hier nicht (wie üblich) der Vergleich der beiden Fassungen dieses königlich-davidischen Danklieds an sich und die Nachzeichnung der Entstehung und Abhängigkeitsrichtung dieser Text-,,Doppelung“ (Diachronie). Vielmehr wird diese als Ausdruck des protokanonischen Ensembles der beiden Bibelbücher verstanden (Synchronie) und soll in ihren Auswirkungen auf die Lesestrategie des Psalmenbuchs (oder jedenfalls einer Teil- bzw. Vorstufe desselben) bedacht werden.

Nun steht diese „Schnittstelle“ zwischen den Büchern Samuel und Psalmen nicht isoliert da, sondern wird flankiert durch weitere Phänomene, die eine Zuordnung der beiden Bücher anzeigen bzw. generieren. Das fängt bereits in Ps 2 an mit der vom Himmelskönig vollzogenen Inauguration und Bevollmächtigung des Zionkönigs. Bleibt auch der Name David ungenannt, so ist die Referenz auf ihn und die Parallelität zwischen Ps 2,7 und 2 Sam 7,14 doch offenkundig. Vollends deutlich ist die Zuordnung der Schriften Samuel und Psalmen aufgrund des mit Ps 3 einsetzenden Präskribierungssystems. Dieses weist eine Vielzahl von Psalmen als לדוד ,zugehörig David“ aus und reichert in einer Anzahl Fälle diese Zuweisung mit biographischen Angaben an. Auf diese Weise wird der jeweilige Psalm einer (oder mehreren) Situation(en) der aus den Samuelbüchern bekannten Geschichtserzählungen zugeordnet. ${ }^{11}$ Dieses Verweissystem unterstützt und unterstreicht nicht nicht nur die besagte Textdoppelung 2 Sam $22 \approx$ Ps 18 , sondern legt auch den eingeschriebenen Richtungsvektor offen (unabhängig von den Entstehungsgegebenheiten der Texte und Bücher im Einzelnen): Der Psalter verweist auf die Samuelbücher, besonders auf dessen David-Texte „zurück“ und setzt die Kenntnis der narrativen, in Sam aufbehaltenen Überlieferung voraus - nicht umgekehrt. Zumindest die Psalmen der ersten beiden David-Sammlungen (Ps 3-41* I Ps 51-72*) innerhalb des Psalters werden dadurch als „Komplementärtexte“ zu den David-Geschichten der Samuelbücher akzentuiert, will heissen: die poetica (Pss) ist Zweitgenre und basiert auf der narratio (Sam). Aufgrund dieser

eingepflanzt an Wasserrinnen « (Psalm 1,3): Beiträge zur Poesie und Theologie von Psalmen und Psalter in Wissenschaft und Kirche (von Beat Weber; hrsg. von Torsten Uhlig; ABG 41; Leipzig: Evangelische Verlagsanstalt, 2014), 332-352.

11 Vgl. dazu Vivian L. Johnson, David in Distress: His Portrait Through the Historical Psalms (LHBOTS 505; New York: T \& T Clark, 2009); Beat Weber, „,An dem Tag, als JHWH ihn rettete aus der Hand aller seiner Feinde und aus der Hand Sauls' (Ps 18,1): Erwägungen zur Anordnung der biographischen Angaben zu David im Psalter," VT 64 (2014): 284-304. 
Davidisierung (und teils auch Messianisierung) vermittelt die Psalmenpoesie den die Psalmen mit David Nachbetenden eine gebetstheologische Vertiefung. ${ }^{12}$

Einige Aspekte der über die Gestalt David laufenden Buchverbindung von Sam und Pss wurden bereits erarbeitet. ${ }^{13}$ Dabei wurde insbesondere deutlich, dass 2 Sam 22 bereits vor seinem Neuerscheinen in der Gestalt von Ps 18 für das Lesen und Verstehen des Psalters vorauszusetzen und im Rahmen einer lectio continua bedeutsam ist. ${ }^{14}$ Bereits beim Übergang von Ps 2 zu Ps 3 wird nämlich der mit Sam vertrauten Rezeptionsgemeinschaft das königlichdavidische Danklied - und zwar in der Gestalt und finalen Position von 2 Sam 22 (und nicht in der von Ps 18, die noch ausstehend ist) - als Verstehenshintergrund aufgerufen. Dabei kommt dem Motiv der Bergung bei JHWH eine besondere, kohäsive Rolle zu.15 Dieser aufgespannte Verstehenshintergrund wird in den nachfolgenden Psalmen durch eine Reihe Signalisatoren bis zum (Neu-)Erscheinen von 2 Sam 22 in der Gestalt von Ps 18 aufrecht erhalten. ${ }^{16}$ Dies führt dazu, dass für die Rezeptionsgemeinschaft des Psalters die zu Beginn notvollen Wege Davids mit häufigen Klagebitten von 2 Sam 22 (und Ps 2) her mit Zuversicht grundiert und mit Hoffnung angereichert werden. Denn wie 2 Sam 22 (V. 1!) ausweist, wird am Ende Gott

12 Vgl. Weber, „An dem Tag,“ 285-288.

13 Vgl. etwa Martin Kleer, »Der liebliche Sänger der Psalmen Israels«: Untersuchungen zu David als Dichter und Beter der Psalmen (BBB 108; Bodenheim: Philo, 1996), 11-127.

14 Das Kolophon in Ps 72,20 setzt implizit einen linear-sequentiellen Leseprozess der (David-)Psalmen voraus. Vgl. dazu auch Frank-Lothar Hossfeld und Till Magnus Steiner, „Problems and Prospects in Psalter Studies,“ in Jewish and Christian Approaches to the Psalms: Conflict and Convergence (hrsg. von Susan Gillingham; Oxford: Oxford University Press, 2013), 244-245.

15 Vgl. dazu Beat Weber, ,,HERR, wie viele sind geworden meine Bedränger ...'(Ps 3,2a): Psalm 1-3 als Ouvertüre des Psalters unter besonderer Berücksichtigung von Psalm 3 und seinem Präskript,“ in Der Bibelkanon in der Bibelauslegung: Methodenreflexionen und Beispielexegesen (hrsg. von Egbert Ballhorn und Georg Steins; Stuttgart: Kohlhammer, 2007), 240-248; Phil J. Botha und Beat Weber, „»Killing Them Softly with this Song ..." The Literary Structure of Psalms 3 and Its Psalmic and Daividic Contexts, " in »Wie ein Baum, eingepflanzt an Wasserrinnen" (Psalm 1,3): Beiträge zur Poesie und Theologie von Psalmen und Psalter in Wissenschaft und Kirche (von Beat Weber; hrsg. von Torsten Uhlig; ABG 41; Leipzig: Evangelische Verlagsanstalt, 2014), 136-138.

16 Vgl. Beat Weber, „Das königlich-davidische Danklied 2 Samuel 22 / Psalm 18 im Kontext von Psalm 1-18: Eine (proto)kanonische Lesung vom Ende der Samuelbücher her zum Anfangsbereich des Psalters hin,“ in „Canterò in eterno le misericordie del Signore " (Sal 89,2): FS Gianni Barbiero (hrsg. von Stefan M. Attard und Marco Pavan; AnBib 3; Rom: Gregorian \& Biblical Press, 2015), 190-197. 
alle Feinde besiegen und die Nöte Davids (sowie die der mit ihm Betenden) zu Ende bringen. ${ }^{17}$

Nachdem der Einfluss der Samuelbücher und insbesondere des königlich-davidischen Danklieds von 2 Sam 22 auf das (textliche) Vorfeld von Ps 18 erarbeitet wurde, soll in diesem Beitrag ergänzend dazu nun dessen Nachfeld in den Blick genommen werden. ${ }^{18}$ Dabei leiten uns Fragestellungen wie: Wird 2 Sam $22 \approx$ Ps 18 in den nachfolgenden Psalmen durch Stichworte ins Gedächtnis gerufen und derart als Verstehenshintergrund wach gehalten? Falls ja, welche Momente und Motive des Psalms werden weitergeführt und in welcher Weise? Inwiefern erfährt der samuelisch-psalterische Doppelpsalm im weiteren Buchverlauf Beachtung und Gewicht?

\section{B DIE BEDEUTUNG VON 2 SAMUEL $22 \approx$ PSALM 18 IM NACHFELD DER PSALTERFORTLESUNG}

\section{Methodische Vorbemerkungen}

Die nachfolgende Evaluierung von Gewichtung und Einfluss, die Ps 18 (// 2 Sam 22) mit Blick auf die ihm nachfolgenden Psalmen im Buch zukommen, bedarf einiger Vorbemerkungen. Zunächst ist festzuhalten, dass keine diachronen Abhängigkeitsverhältnisse untersucht werden. Vielmehr wird synchron auf der Buchebene der Frage nachgegangen, ob, in welchem Mass und in welcher Weise im Rahmen der lectio continua der markante Ps 18 in den nachfolgenden Psalmen „Spuren“ hinterlässt. Es wird also nach Indizien gefragt, die es wahrscheinlich machen, dass in Rezeptions- und Memorierungsvorgängen Rückbezüge zu diesem Psalm hergestellt werden (können). Dazu kann auf methodische Überlegungen und materiale Vorgaben von Barbiero und Ballhorn zurückgegriffen werden. ${ }^{19}$ Anders als bei Ballhorn wird freilich nicht der gesamte Rezeptionsprozess in den Blick genommen, sondern lediglich ein Ausschnitt. Bei einer derartigen Beschränkung und zugleich Fokussierung (unter Abblendung anderer Momente) ist dabei die Gefahr der „Überschärfe“ im Auge zu behalten.

Ein wesentlicher Ausgangspunkt für unsere Untersuchung liegt in einem Textsignal bzw. einer Rezeptionsvorgabe in der Bucheinleitung: Die Hör- und Betgemeinschaft des Psalters wird nämlich mittels einer Seligpreisung zu einer durch Wiederholung, Memorierung und Meditierung zu vollziehende Aneig-

17 Vgl. Weber, „Das königlich-davidische Danklied,“ 198-199.

18 Die Fragestellung wurde in der Vorfeld-Studie zu Ps 18, Weber, „Das königlichdavidische Danklied,“ 198199, als Forschungsdesiderat notiert.

19 Vgl. Gianni Barbiero, Das erste Psalmenbuch als Einheit: Eine synchrone Analyse von Psalm 1-41 (ÖBS 16; Frankfurt a. M.: Peter Lang, 1999); Egbert Ballhorn, Zum Telos des Psalters: Der Textzusammenhang des Vierten und Fünften Psalmenbuches (Ps 90-150) (BBB 138; Berlin: Philo, 2004). 
nung der JHWH-Wegweisung angewiesen und zugleich in sie eingewiesen (vgl. Ps 1,1-2). Mit der תורת יהוה ist das Psalmenbuch (mit)gemeint. Dieses wiederum verweist auf ihm vorgelagertes autoritatives Schrifttum und spannt derart einen kanonhermeneutischen Horizont auf. ${ }^{20}$

Im Blick auf unsere Fragestellung wird methodisch so vorgegangen, dass wesentliche, im Nachfeld von Ps 18 auf diesen Psalmen verweisende Momente zusammengestellt und ausgewertet werden. Zunächst wird eine Auswahl prägnanter Begriffe und Motive aufgelistet. ${ }^{21}$ Sie ergeben mögliche „Knotenpunkte“, die dann näher evaluiert werden. Wie viele „Momente“ zur Herstellung und Wachhaltung von Ps 18 (bzw. Passagen daraus) in den Folgepsalmen im Einzelnen nötig sind, lässt sich nur approximativ bestimmen. Unter Zuhilfenahme der drei nachfolgend genannten Kriterien können gleichwohl hinreichende Aussagen in einer gewissen Bandbreite gemacht werden:22

(i) Kumulation: Je mehr sprachliche Elemente zwischen den Psalmen übereinstimmen, je grössere Schnittstellen vorliegen, desto stärker ist die Wahrscheinlichkeit der memorativen Evozierung. ${ }^{23}$

(ii) Distinktion: Je spezifischer und charakteristischer (und seltener) wiederkehrende Begriffe und Wendungen sind, desto mehr ist eine Verknotung im Rezeptionsprozess anzunehmen.

(iii) Distanz (Buchkontext): Im Fortlauf des Psalters ist mit zunehmender literarischer Distanz zu Ps 18 eine Abnahme des memorativen Potentials anzunehmen - es sei denn, dass Ps 18 durch verstärkt auftretende

20 Angezeigt wird dieser etwa durch die Verweise auf David in den Psalm-Präskripten, dazu Weber, „An dem Tag.“ Neben der Gestalt Davids und den mit ihm verbundenen Traditionen (Sam) verdient auch Mose und das ihm zugeordnete Wort (Tora) Erwähnung, vgl. Beat Weber, „Psalm 78 als »Mitte« des Psalters? - ein Versuch," in »Wie ein Baum, eingepflanzt an Wasserrinnen " (Psalm 1,3): Beiträge zur Poesie und Theologie von Psalmen und Psalter in Wissenschaft und Kirche (von Beat Weber; hrsg. von Torsten Uhlig; ABG 41; Leipzig: Evangelische Verlagsanstalt, 2014), 399-409.

21 Dies geschieht in Fortführung und Ausweitung der in der FS Barbiero erstellten Liste zum Vorfeld (vgl. Weber, „Das königlich-davidische Danklied,“ 193).

22 Vgl. dazu die umfangreicheren Überlegungen bei Ballhorn, Zum Telos, 17-31.

23 Ohne hier in eine Diskussion über die Einheitlichkeit von Ps 18 eintreten zu wollen, kann als Konsens gelten, dass es sich um einen „kompositen“ Text und Grosspsalm insofern handelt, als unter der Leitgattung der Toda verschiedene literarische Formen und Traditionen vereint sind. Dazu gehören eine GewitterTheophanie und weisheitliche Passagen. Aus diesem Grund ist es ratsam, das Augenmerk auch darauf zu lenken, welche Teile des Psalms wo und wie anklingen (und welche nicht). 
Weber, „Gelobt sei der HERR, mein Fels ...!“ OTE 29/1 (2016): 195-220

Verbindungsmomente (siehe 1. und 2.) neu bzw. verstärkt ins Gedächtnis gerufen wird.

\section{Gemeinsame Begriffe und Motive (Auswahl)}

Das textliche Nachfeld von Ps 18 wird in folgenden, die Buchstruktur mitberücksichtigenden Einheiten gelistet, gestaffelt erarbeitet und ausgewertet: 1. Ps 19-24 (verbleibender Umfang der Kleingruppe Ps 15-24); 2. Ps 25-41 (verbleibender Umfang des Psalterteilbuchs I); 3. Ps 42-72 (Teilbuch II); 4. Ps 73-89 (Teilbuch III); 5. Ps 90-150 (Teilbücher IV und V). ${ }^{24}$

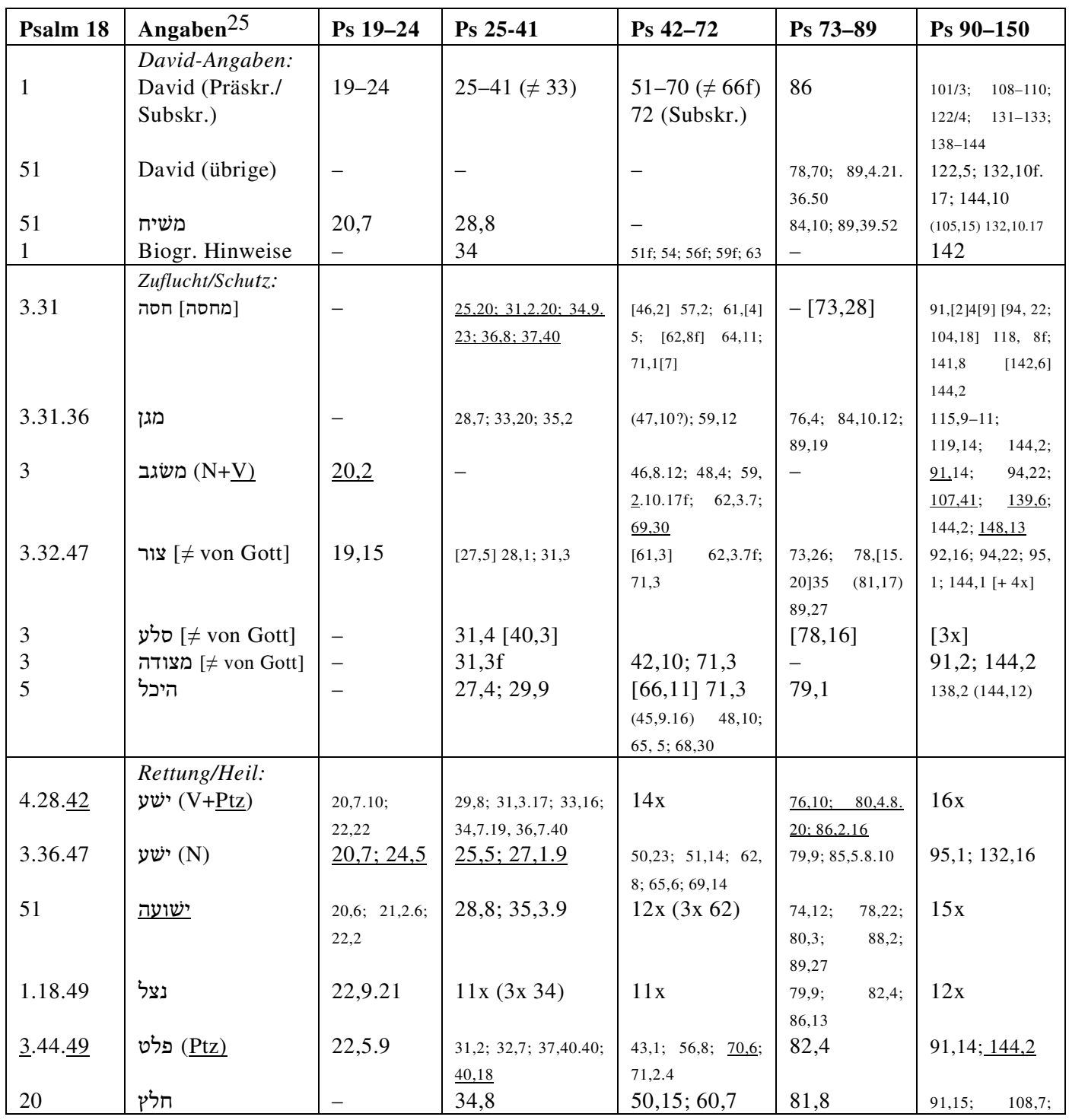

${ }^{24}$ Aufgrund des Platzbedarfes wird z. T. eine kleinere Schriftgrösse verwendet.

25 Verwendete Abkürzungen: $\mathrm{N}=$ Nomen; $\mathrm{P}=$ Personbezeichnung; Ptz = Partizip; $\mathrm{S}$ $=$ Sachbezeichnung; $\mathrm{V}=$ Verb . 
204 Weber, „Gelobt sei der HERR, mein Fels ...!“ OTE 29/1 (2016): 195-220

\begin{tabular}{|c|c|c|c|c|c|c|}
\hline & & & & & & $\begin{array}{l}116,8 ; 119,153 ; \\
140,2\end{array}$ \\
\hline $\begin{array}{l}1.4 .18 .38 . \\
41.49\end{array}$ & $\begin{array}{l}\text { Feinde/Not: } \\
\text { איב }\end{array}$ & 21,9 & $13 x(3 x 41)$ & $19 x(3 x 68)$ & $11 x(4 x 89)$ & $14 \mathrm{x}(3 \mathrm{x} 143)$ \\
\hline$\underline{18.41}$ & שנא (ㄹtz) & $\underline{21,9}$ & $8 x(\underline{4 x})$ & $8 x(\underline{6 x})$ & $\begin{array}{l}\underline{81,18: \quad 83,3 ;} \\
\underline{86,17 ; 89,24}\end{array}$ & $\begin{array}{l}15 x(\underline{6 x}) \\
(4 \times 119)\end{array}$ \\
\hline 7 & צרר / I (S) & - & 31,$10 ; 32,7$ & 59,$17 ; 66,14 ; 69,18$ & & $7 \times(4 \times 107)$ \\
\hline 38 & רדף + Feinde o. ä. & - & 31,$16 ; 35,3.6 ; 38,21$ & 69,$27 ; 71,11$ & 83,16 & $8 \mathrm{x}(5 \mathrm{x} 119)$ \\
\hline 49 & חמס & - & 25,$19 ; 27,12 ; 35,11$ & 55,$10 ; 58,3 ; 72,14$ & 73,$6 ; 74,20$ & $140,2.5 .12$ \\
\hline 7.42 & שוע & 22,25 & 28,$2 ; 30,3 ; 31,23$ & 72,12 & 88,14 & 119,147 \\
\hline 5 & אפף & - & 40,13 & - & & 116,3 \\
\hline 5 & בליעל & - & 41,9 & - & & 101,3 \\
\hline 5.6 & חבל II & - & - & & $(78,55)$ & $\begin{array}{l}(105,11) \quad 116,3 ; \\
119,61 ; 140,6\end{array}$ \\
\hline $39 . \underline{40.49}$ & $\begin{array}{l}\text { Aufstehen/erheben: } \\
\text { קום ( } \underline{\mathrm{Ptz}})\end{array}$ & 20,$9 ; 24,3$ & $8 \mathrm{x}$ & $\begin{array}{ll}\underline{44,6} .27 ; & 54,5 \\
\underline{59,2} ; 68,2 & \end{array}$ & $9 \mathrm{x}(\underline{1 \mathrm{x}})$ & $15 x(\underline{2 x})$ \\
\hline 28.47 .49 & רום & 21,14 & $\begin{array}{l}27,5 f . ; \quad 30,2 ; \quad 34,4 ; \\
37,34\end{array}$ & $\begin{array}{l}46,11 ; \quad 57,6.12 \\
61,3 ; 66,7\end{array}$ & $\begin{array}{l}13 \times(5 \times 75 \\
6 x 89)\end{array}$ & $17 x(3 x 99)$ \\
\hline 17 & מרום & - & - & 56,$3 ; 68,19 ; 71,19$ & 73,$8 ; 75,6$ & $\begin{array}{l}92,9 ; 93,4 ; 102, \\
20 ; 144,7 ; 148,1\end{array}$ \\
\hline $\begin{array}{l}26[26.51] \\
24.26[26] . \\
31.33\end{array}$ & $\begin{array}{l}\text { Personbezeichn.: } \\
\text { [סד/תמסד [סמם] תמים }] \\
\end{array}$ & $\begin{array}{l}-[23,6] \\
19,8[14]\end{array}$ & $\begin{array}{l}4 \mathrm{x}[16 \mathrm{x} \text { (je } 3 \mathrm{x} 25 ; \\
31 ; 33 ; 36)] \\
{[25,21 ; 26,1.11]} \\
37,18[37][41,13]\end{array}$ & $\begin{array}{l}3 x[17 x(3 x 59)] \\
-[64,5.7]\end{array}$ & 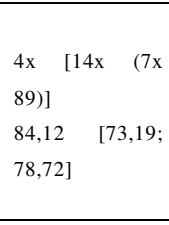 & $\begin{array}{l}10 x(3 x 149)[> \\
70 x(26 x 136)] \\
101,2[2] 6 ; 119, \\
1.80 \quad[102,28 ; \\
104,35]\end{array}$ \\
\hline 21.25 .27 & $\begin{array}{l}\text { Diverse: } \\
\text { בר/ברר }\end{array}$ & 19,$9 ; 24,4$ & - & - & 73,1 & - \\
\hline 21.25 & צדק & 19,$10 ; 23,3$ & $\begin{array}{l}35,24.27 f ; \quad 37,6 \\
40,10\end{array}$ & $10 \mathrm{x}$ & $\begin{array}{l}82,3 ; 85,11 f .14 ; \\
89,15\end{array}$ & $21 \mathrm{x}(12 \mathrm{x} 119)$ \\
\hline 23 & משפט & 19,10 & $\begin{array}{l}25,9 ; 33,5 ; 35,23 \\
36,7 ; 37.6 .28 .30\end{array}$ & 48,$12 ; 72,1 \mathrm{f}$ & $\begin{array}{l}76,10 ; 81,5 ; 89, \\
15.31\end{array}$ & $41 \mathrm{x}(23 \mathrm{x} 119)$ \\
\hline 50 & זמר // ידה & - & $30,5.13 ; 33,2$ & 57,$10 ; 71,22$ & - & $\begin{array}{ll}92,2 ; & 108,4 ; \\
138,1 & \end{array}$ \\
\hline 10.34 .39 & רגל & 22,17 & $6 \mathrm{x}$ & $5 x(2 \times 66)$ & 73,2 & $13 x(3 x 119)$ \\
\hline$\underline{20.37}$ & רחב/מרחב & - & 25,$17 ; \underline{31,9 ; 35,21}$ & 55,12 & 81,11 & $\underline{118,5}+6 x$ \\
\hline 7 & שמע + קרא & - & $\begin{array}{l}27,7 ; 28,1 f ; 30,9.11 ; \\
34,7\end{array}$ & $55,17 \mathrm{f} ; 61,2 \mathrm{f}$ & - & $\begin{array}{l}102,2 \mathrm{f} ; \quad 116,1 \mathrm{f} ; \\
130,1 \mathrm{f} ; 145,18 \mathrm{f}\end{array}$ \\
\hline 22.31 .33 & (N) דרך (N) & - & $14 \times(4 \times 25,5 \times 37)$ & $\begin{array}{l}49,14 ; 50,23 ; 51 \\
15 ; 67,3\end{array}$ & $7 \mathrm{x}$ & $\begin{array}{l}31 \mathrm{x}(4 \mathrm{x} 107,13 \mathrm{x} \\
119)\end{array}$ \\
\hline 8 & רעש ארץ & - & - & 60,$4 ; 68,9(72,16)$ & 77,19 & - \\
\hline 8 & רגז & - & - & - & $77,17.19$ & 99,1 \\
\hline 9.13 .14 & נחלים & - & - & - & - & 120,$4 ; 140,11$ \\
\hline 10 & ערפל & - & - & - & - & 97,2 \\
\hline 11 & כרוב & - & - & - & 80,2 & 99,1 \\
\hline 14 & רעם (V+N) & - & 29,3 & - & 77,$19 ; 81,8$ & 96,$11 ; 98,7 ; 104,7$ \\
\hline $15 . \underline{15}$ & ברק / חץ & - & 38,3 & $5 x(2 \times 64)$ & $77,18 . \underline{19}$ & $\begin{array}{l}97,4 ; 120,4 ; 127 \\
4 ; 135,7 ; 144,6.6\end{array}$ \\
\hline$\underline{16}$ & נער/ה & - & - & 68,31 & $\underline{76,7 ; 80,17}$ & $\frac{104,7 ;}{119,21} \quad 106,9 ;$ \\
\hline 28 & שפל (V+N) & - & - & - & 75,8 & $\begin{array}{l}113,6 ; \quad 136,23 \\
138,6 ; 147,6\end{array}$ \\
\hline 39 & מחץ & - & - & $68,22.24$ & - & $110,5 \mathrm{f}$ \\
\hline 40 & כרע & 20,$9 ; 22,30$ & - & 72,9 & 78,31 & 95,6 \\
\hline 41 & צמת & - & - & 54,$7 ; 69,5$ & 73,$27 ; 88,17$ & $\begin{array}{l}94,23 ; \quad 101,5.8 \\
119,139 ; 143,12\end{array}$ \\
\hline 43 & טיט & - & 40,3 & 69,15 & - & - \\
\hline$\underline{48}$ & נקם / נקמה & - & - & 44,$17 ; 58,11$ & $\underline{79,10}$ & $\underline{94,1 ; 99,8 ; \underline{149,7}}$ \\
\hline
\end{tabular}




\section{$3 \quad$ Auswertung des Befunds}

\section{3a Psalm 18 und seine Aufnahme und Bedeutung in Psalm 19-24}

Alle zehn Psalmen der Kleingruppe Ps 15-2426 werden als לדוד, zugehörig David“ ausgewiesen. Ps 18, der mit Abstand längste Psalm unter ihnen und der drittlängste im Buch, ist aber der einzige, der darüber hinaus am Textende (V. 51) eine David-Erwähnung enthält und der aufgrund seines Präskripts (V. 1) im Leben Davids situiert wird.

Was die Verbindungen des Nachbarn Ps 19 zu Ps 18 betrifft, so liegen Schnittstellen hinsichtlich der Tora-weisheitlichen bzw. frömmigkeitlichen Formulierungen der beiden Psalmen vor. ${ }^{27}$ Die frömmigkeitlichen, auf David bezogenen Aussagen in Ps 18 werden im Folgepsalm gleichsam theologisch verankert (19,8, vgl. 1,2). Vollkommenheit und Reinheit eignet der Tora - und dem König insofern, als er sein Handeln und Verhalten auf sie abstellt (in der Linie des Königsgesetzes, vgl. Dtn 17,18-20). Wie Dtn 32,4 ausweist, ist das

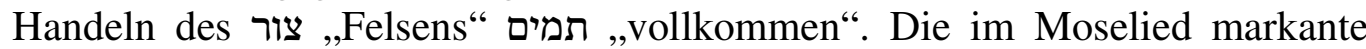
„Fels“-Prädikation für JHWH findet sich bekanntlich auch im königlichdavidischen Danklied 2 Sam 22 // Ps 18. Innerhalb des Psalters handelt es sich bei 18,3.32.47 zugleich um die Erstbelege; ihnen folgt in 19,15 der nächste Beleg (der übernächste erst in Ps 27). Das „Fels“-Bekenntnis ergeht in Ps 19 von „deinem Knecht“ $(19,12.14)$. Auch der Knechtsbegriff liegt in diesen beiden Psalmen das erste Mal im Buch vor (bei Ps 18 im Präskript). In der Sequenz Ps 18 לעבד יהוה 18 wird die Psalmzuweisung über Ps „Zugehörig dem Knecht JHWHs“ (V. 1) in der Selbstbezeichnung des Sprechers als „dein Knecht“ (V. 12.14) in Ps 19 aufgenommen. Das zuvor Ausgeführte wird fortgeführt, die Tora-Verpflichtung Davids unterstrichen und zugleich die „triumphalistische“ Spitze von Ps 18 gebrochen (vgl. 18,21-25 mit 19,12-15). Die Zuweisung von Ps 18 (auch) an den „Knecht JHWHs“ ist gegenüber 2 Sam 22,1 ein neues Element. Es verweist nicht allein auf David, sondern verbindet zugleich mit Mose (vgl. Dtn 34,5; Jos 1,1.13.15 u. ö.), für den die Ehrentitulatur gebräuchlich(er) ist (für David sonst nur noch Ps 36,1). Dergestalt wird auch die Analogie zwischen Moselied (Dtn 32) und Davidslied (2 Sam $22 / /$ Ps 18) verstärkt. ${ }^{28}$ Der Psalter ist (ähnlich wie die Chronik) gegenüber den Samuelbüchern bemüht, David gleichsam „mosaisch“ und d. h. auf die Tora zu gründen. Ausdruck dafür ist auch die Nachbarstellung von

26 Zur Bestimmung der Kleingruppe Ps 15-24 vgl. Philip Sumpter, „The Coherence of Psalm 15-24,“ Bib 94 (2013): 186-209; Weber, Werkbuch Psalmen III, 161-163, zum Vorfeld von Ps 18 innerhalb der Gruppe (Ps 15-17) vgl. Weber, „Das königlichdavidische Danklied,“193-196.

27 Vgl. צדק : 18,21.25; 19,9; תמים 18,24.26.31.33; 19,8(.14), weniger distinktiv 18,21.25; 19,10; משפט 18,23;19,10.

28 Vgl. dazu Dominik Markl, Gottes Volk im Deuteronomium (BZAR 18; Wiesbaden: Harrassowitz, 2012), 252-258. 
Ps 19 (fokussiert im Zentrum der Kleingruppe) nach Ps 18. Dazu gehören die Knechtsbezüge in Ps 19 sowie - in Rückbindung an den Pentateuch - das Loblied auf JHWH als Schöpfer und Tora-Spender.

Es folgen in der Leseabfolge zwei Königspsalmen, die gattungsmässig und in der chiastischen Anlage von Ps 15-24 stärker mit Ps 18 als mit Ps 19 korrelieren. ${ }^{29}$ Gegenüber dem königlich-davidischen Danklied bieten die „bescheideneren“ Psalmen 20 und 21 eine Reduktion an Tonalität, Intensität und Finalität - jedenfalls gegenüber der Fassung 2 Sam 22 innerhalb der Samuelbücher mit hervorgehobenem Genre und Endposition. Bei Ps 18 ist die Gestalt weithin dieselbe, aber innerhalb des Psalters kommen die genannten Fokussierungen nicht zum Tragen: Die Poesie ist auch die der Textumgebung, und die Platzierung innerhalb des Gesamtbuches ist weit „gewöhnlicher" und damit unbetonter als in der Samuelbücher-Fassung. Die zu 2 Sam 22 passende Finalität der Aussage, dass JHWH David aus der Hand aller seiner Feinde und aus der Hand Sauls rettete (2 Sam 22,1), ist zwar beibehalten (Ps 18,1), aber in der Folge durch Psalmen mit neuerlichen Feind-Konstellationen „fortgeschrieben“ und derart abgeschwächt. Die Fortlesung durch die Königspsalmen 20 und 21 trägt das ihre $\mathrm{zu}$ diesem decrescendo bei: Die Königsthematik ist allerorts gegeben (מלך 18,51; 20,10;21,2.8; משיח 18,51; 20,7). Ebenso finden sich Kampf-, Feind- und vor allem Rettungsaussagen (häufig mit Derivaten der Wurzel ישע: 18,3.4.28.36.42.47.61; 20,6.7.10; 21,2.6). Gegenüber Ps 18 sind in Ps 20 und v. a. Ps 21 jedoch die martialischen und triumphalistischen Aspekte zurückgenommen. Ist der Bogen in Ps 18,35.41 siegreich in Davids Hand und sind die Feinde auf der Flucht, so sind ähnliche Aussagen in 21,13 stärker theologisch überblendet und oszillieren zwischen David und JHWH als Subjekt. Nicht mehr das Kampfgerät mit Wagen und Rossen steht im Vordergrund, sondern die Proklamation des JHWH -Namens (20,8). Damit liegen (neuerdings) Anklänge an das dtn Königsgesetz vor (vgl. Dtn 17,16-20); zudem weisen diese Psalmen schon in die Richtung ,geistlichliturgischer Kampfführung“, wie sie (später) etwa in $2 \mathrm{Chr} 20$ greifbar wird. Ist in Ps 18 der triumphierende König der Sprechende, bieten Ps 20 und 21 vornehmlich an Gott gerichtete Worte über den König (Gebet). Die Rettung ist damit nicht mehr ihm allein und seiner Gottesbeziehung zuzuschreiben, sondern fürbittend in die Hände des Volkes Israel gelegt.

Zuletzt ein Blick von den Schlusspsalmen Ps 22-24 der Gruppe Ps 15-24 zurück zu Ps 18. Das Moment der „Beugung“ der Feinde verbindet die erste mit der zweiten Hälfte der Kleingruppe (כרע 17,13; 18,40; 20,9; 22,30). Der Kontrast von Ps 22 (gottverlassen, ein ,Wurm“) zu den vorausgehenden Königspsalmen, insbesondere Ps 18, ist überaus stark. Die Rettungsbegriffe sind den in Ps 18 verwendeten ähnlich, freilich wird damit nicht Rettung

29 Eine Zusammenstellung der Parallelen bietet Barbiero, Das erste Psalmenbuch, 234-240. 
bezeugt, vielmehr liegt diese zurück bzw. wird neu erbeten (vgl. 22,2.5.9.21). Damit lässt sich sagen: Die in Ps 18 als ,besiegt“ bezeugten Feinde sind zurück! Man wähnt sich an die Anfänge des Psalterbuchs mit seinen gehäuften Klagebitten zurückversetzt. Das Vertrauen vom Ende her (wie Ps 18 zeigt) und auf das Ende hin wird freilich durch das anschliessende Danklied 22,23-32 in gewisser Weise reaktualisiert. Damit verbunden ist allerdings eine Akzentverlagerung vom David- auf das JHWH-Königtum $(22,29)$ - ein Moment, das im abschliessenden Ps 24 nochmals zum Tragen kommt (V. 7-10).

Fazit: Berührungen mit Ps 18 finden sich in Ps 19-24 vornehmlich in den drei nachfolgenden Psalmen. Im Lichte von Ps 19-21 wird der Siegestriumph Davids über seine Feinde verstärkt Gott selbst zugewiesen und David an Moses Tora gewiesen. Die Konturen des von 2 Sam 22 her bedeutungsgeladenen Ps 18 werden abgemildert und neu akzentuiert (Entmilitarisierung, Theologisierung). Zudem wird - anders als in der SamuelFassung - der mit Ps 18 erreichte Kulminationspunkt des Gott-gewährten Königstriumphs im Psalterfortgang überschritten. Er lässt sich in der Fortlesung zwar reaktualisieren, die in ihm zum Tragen kommende Potenz und Dominanz des Königs wird aber abgemildert.

\section{3b Psalm 18 und seine Aufnahme und Bedeutung in Psalm 25-41}

Nach den Ps 18 unmittelbar nachfolgenden Psalmen der Kleingruppe Ps 15-24 nehmen wir die verbleibenden Psalmen des ersten David-Psalters (Teilbuch I) in den Blick. Was biographische Hinweise in den David-Psalmen betrifft, ist deren Fehlen bzw. Ausbleiben nach Ps 18 zu notieren. Erst in Ps 34 erscheint das nach Ps 18 nächste und zugleich einzige Präskript mit Situationsangabe innerhalb des verbliebenen ersten David-Psalters. In 34,1 wird explizit, was in der Fortlesung des Psalters nach Ps 18 in Ps 22 und dann öfters zutage getreten ist: Es wird hinter die in 18,1 angezeigte Finalität der Rettung zurückgegangen - auf ein Geschehen, das noch vor seinem Königsantritt liegt (Saul-DavidKonflikt). ${ }^{30}$

Das im königlich-davidischen Danklied 2 Sam 22 // Ps 18 stark akzentuierte Motiv-Cluster „JHWH als Zuflucht“ ist diejenige Thematik, die in der Folge am stärksten weitergeführt wird und diesbezüglich Ps 18 repetiert und variiert. ${ }^{31}$ Es fällt auf, dass von allen Teilen des Psalters der erste David-Psalter die höchste Dichte dieser Begrifflichkeit enthält. Die Zufluchts-Semantik findet sich zwar bereits im Vorfeld von Ps $18,{ }^{32}$ doch sticht dieser als derjenige Psalm

30 Vgl. Weber, „An dem Tag,“ 294-295.

$31 \mathrm{Vgl}$. Jerome F. D. Creach, Yahweh as Refuge and the Editing of the Hebrew Psalter (JSOTSup 217; Sheffield: Sheffield Academic Press, 1996). Creach hat in seiner Studie das um חסה gelagerte Wortfeld innerhalb des Psalters analysiert, die Belege aufgelistet und wesentliche Einsichten zusammengetragen.

32 Vgl. Weber, „Das davidisch-königliche Danklied.“ 
heraus, der die Thematik erstmals prägnant zur Sprache bringt. In den unmittelbar anschliessenden Psalmen der Kleingruppe Ps 15-24 erscheint die Motivik wenig profiliert. ${ }^{33}$ Mit Ps 25 , der die nächste Teilgruppe eröffnet (Ps 25-34), erfährt sie dann aber neuerdings Gewicht. In diesem alphabetischen Akrostichon wird erstmals nach Ps 18 der Leitbegriff חסה ,sich bergen“ $(25,20$, vgl. 18,3.31) aufgegriffen. Es ist zudem der erste Psalm im Psalter, der ihn mit dem zweiten Leitbegriff der Motivgruppe, בטח, ,vertrauen“ (25,2), gemeinsam erwähnt und strukturell verknüpft (Psalm-Rahmen). ${ }^{34}$ Mit Ps 18 verbindet Ps 25 als David-Psalm überdies Gottes Retten (vgl. 25,5.20 mit 18,1.3.18.36.47.49) und den Begriff רחב hi ,weit machen“ (18,37; 25,17, vgl. auch 18,20). Auch frömmigkeitliche und ethische, vom Nachfolgepsalm 19 verstärkte Momente teilt Ps 18 mit Ps 25 und seinem Nachbar Ps 26 (vgl. 18,21-28.31.33 mit 25,9.21; 26,1.6.11).

Die Psalmen 27 und noch mehr 28 - namentlich 28,7-8 (mit משיחו „seinem Gesalbten“ 18,51; 28,8) - bieten ebenfalls mit Ps 18 gemeinsame Zufluchts- und Heilsmotivik: JHWH als צור „Fels“ 18,3.32.47; 28,1 (vgl. 27,5), der Begriff מגן,Schild“, die Korrespondenz von menschlichem Rufen und Gottes Antworten (vgl. 18,7 mit 27,7; 28,1-2) sowie insbesondere Derivate der Wurzel 18,3.4.28.36.47.51; 27,1.9; 28,8.9).

Die Berührungen der weiteren Psalmen innerhalb des ersten David-Psalters mit Ps 18 sind überwiegend wenig distinktiv. Ausnahmen bilden Ps 31 und in geringerem Mass die Psalmen 3435 und 37. Namentlich der Eingangsteil Ps 31,2-4 weist signifkante Berührungen mit Ps 18 auf, wobei sich Bitte und Bezeugung verschränken. Die Parallelen zwischen Ps 18 und Ps 31; 34; 37 umschliessen Zufluchts-Topik ${ }^{36}$, die Rettung aus Bedrängnis bzw. aus der Hand von Bedrängern ${ }^{37}$ und anderes mehr. ${ }^{38}$

33 Vgl. חסה Ps 17,7; צור Ps 19,15. Das allgemeinere בטח,,vertrauen“ findet sich in Ps 16,9 und den anderen beiden Königspsalmen (Ps 21,8; 22,5.6.10), aber nicht in Ps 18.

34 Vgl. Beat Weber, Werkbuch Psalmen II. Die Psalmen 73 bis 150 (Stuttgart: Kohlhammer, 2003), 132-134, ähnlich Pieter van der Lugt, Cantos and Strophes in Biblical Hebrew Poetry: With Special Reference to the First Book of the Psalter (OtSt 53; Leiden: Brill, 2006), 266. Erstmals im Psalter erscheint zudem das mit dem Wortfeld verwandte Lexem קוה,hoffen, harren“ (Ps 25,3.5.21).

35 Zur David-Biographie dieses Psalms s. o.

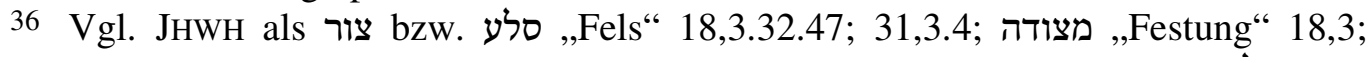
31,3.4; 18,3.31; 31,2.20; 34,9.23; 37,40. Die Verbindung von ,alle“ (כלה) und (2), dem Partizip von חסה findet sich 3mal im Psalter (Ps 2,12; 18,31; 34,23) und ansonsten nur noch in 2 Sam 22,31 (vgl. Creach, Yahweh as Refuge, 76).

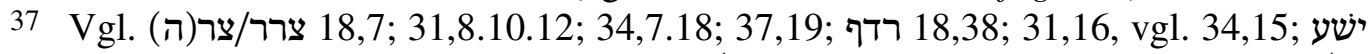

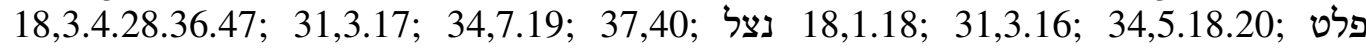
18,3.44.49; 31,2; 37,40; 18,20; 34,8. 
Fazit: Die bereits zu Ps 19-24 notierten Beobachtungen setzen sich fort. Ps 18 ,verliert“ im weiteren Nachfeld des Psalters weiter von der ihm von der Danklied-Fassung 2 Sam 22 her eignenden Charakteristik und Finalität. Doch insbesondere in den Psalmen 25; 28; 31; 34; 37 klingt die in Ps 18 laut gewordene Bezeugung von JHWH als Zuflucht, verbunden mit Rettungs- und Frömmigkeitsaussagen, nach.

\section{3c Psalm 18 und seine Aufnahme und Bedeutung in Psalm 42-72}

Die Unterbrechung der David-Zuschreibungen durch Gilden-Psalmen (Qorachiten Ps 42-49, Asaph Ps 50) im Psalterfortlauf distanziert zusätzlich von Ps 18. Mit Ps 51 setzt dann ein zweiter, bis Ps 72 reichender David-Psalter ein. Darin finden sich die bei Ps 18 und dann Ps 34 letztmals vorliegenden biographischen Präskript-Angaben gehäuft (schwergewichtig in der ersten Hälfte). Abgesehen vom Bathseba/Salomo-Rahmen (Ps 51/72) stehen Geschehnisse der Konfliktlage mit Saul im Fokus (Ps 52; 54; 56; 57; 59), ${ }^{39}$ der in Ps 52,2 erstmals nach Ps 18,1 erwähnt wird. ${ }^{40}$ Im Unterschied zu Ps 18 sind die angeführten Psalmen aus dem zweiten David-Psalter in Konflikten angesiedelt und blicken (noch) nicht auf die Rettung JHWHs aus der Hand Sauls zurück. Trotz dieser (schon bei Ps 34 und weiteren Psalmen konstatierten) Rückkehr hinter das in Ps 18 im Lichte seines Präskripts besungene siegreiche Ende ist eine Nachwirkung des königlich-davidischen Danklieds im Prozess des Nachbetens und Meditieren des Psalters anzunehmen: Dass Gott am Ende den Sieg behält gegenüber den Feinden Davids und seines Volkes mag zumindest als vormals gehörte Botschaft - in Ohr und Herz nachklingen und Zuversicht mitten in Konflikten stiften.

Über diese Saul-Erwähnungen und -Geschehnisse hinaus ist der Nachhall von Ps 18 im zweiten David-Psalter eher gering. Bemerkenswert ist, dass im Fluchtpsalm vor Saul (Ps 57,1) zu Beginn (V. 2) Zufluchts- und am Ende Lobpreis-Begrifflichkeit erscheint, die dieser Psalm mit Ps 18 teilt. ${ }^{41}$ Ansonsten ist die Bergungs-Motivik weniger präsent als im ersten DavidPsalter. Erwähnung verdienen neben Ps 57 noch Ps 61, das teils wiederholte Bekenntnis in Ps 62 (V. 2-3.6-8) sowie Ps 71-72 am Schluss. In Ps 61 wird das Schreien zu Gott (61,2-3 wie 18,7) mit der Zuflucht bei Gott verbunden (מחסה 18,3.31; 61,4-5). Oszilliert in Ps 61,3 der ,erhöhte Felsen" zwischen realem und metaphorischem Sinn, so erscheint im

38 Vgl. שוע 18,7.42; 31,23; מרח 18,28.47.49; 34,4; 37,34; משפט ind 18,21.23.25; 37,6(.28.30).

39 Vgl. dazu ausführlich Weber, „An dem Tag,“289-301.

40 Alle vier Belege zu Saul innerhalb des Psalters finden sich in Präskripten.

41 Vgl. ימסה 18,3.31; 57,2; Lobpreis unter den Völkern unter Verwendung der Verben 1. Person jqtl von ידה in 18,50; 57,8.10, ferner רום 18,28.47.49; $57,6.12$. 
nachfolgenden Psalm צור wie in Ps 18 ebenfalls 3mal als Gottesprädikation (vgl. 18,3.32.47; 62,3.7.8). ${ }^{42}$

Der nicht präskribierte Ps 71, eröffnend mit בך־יהוה חסיתי ,In dir, JHWH, habe ich mich geborgen ..." (vgl. auch Ps 31,2), hat die stärksten, mit Ps 31 teils identischen Affinitäten zu Ps 18 in den Bergungs- und Rettungsaussagen zu Beginn. Zudem liegen vom eher seltenen Begriff מצודה ,Festung“ vier der insgesamt sieben Belege im Psalter in diesen drei Psalmen vor (Ps 18,3; 31,3.4; 71,3). Bei der Rede vom „Fels“ finden sich die Varianten צור und beieinander in Ps 71,3 (vgl. Ps 31,3-4), der Entlehnungsspuren von Ps 18,3 aufweist. Etwas weniger auffällig ist die mit Ps 18 geteilte Rettungsbegrifflichkeit. ${ }^{43}$ Gottes gerechtes Handeln geschieht aus der bzw. reicht bis zur „Höhe“ (מרום 18,17; 71,19). Entsprechend wird JHWH vom sprechenden Ich musikalisch gepriesen (זמר/ידה 18,50; 71,22).

Der Salomo (,für Salomo“) zugewiesene Ps 72 gilt wie Ps 18 als dezidierter Königspsalm. Innerhalb der Buchgestalt (oder bereits einer Vorstufe תפלות דוד derselben) kommt ihm am Schluss des zweiten David-Psalters, ja der „Klagebitten Davids“ insgesamt (vgl. das Kolophon Ps 72,20), eine vergleichbare Stellung zu wie 2 Sam 22 in den Samuelbüchern. Beiden Psalmen ist überdies eine gewisse Programmatik eigen, Ps 18 hinsichtlich der militärischen Überlegenheit (Aussenbezug), Ps 72 stärker hinsichtlich der Durchsetzung der göttlichen Rechtsordnung (Innenbezug). Gottes Beugung der Widersacher (כרע 18,40; 72,9, vgl. auch 20,9) findet sich in beiden Psalmen. Ansonsten berühren sich Aussagen über Recht, Frömmigkeit und Einsatz für die Bedürftigen im Volk mit entsprechenden Passagen in Ps 18 (vgl. 18,21-28 mit 72,1-4.12-14), freilich mit je unterschiedlichen Akzenten. In Ps 18,7(42) geschieht das Schreien (שוע) zu Gott vom König selbst, in Ps 72,12 schreien die Elenden, und der König (und/oder JHWH) soll helfen.

Fazit: Der Nachhall von Ps 18 verringert sich in der Psalterfortlesung aufgrund der zunehmenden „Distanz“, die durch den Einschub von GildenPsalmen zwischen die David-Sammlungen noch ,gedehnt“" wird. Die Erwähnung Sauls in einigen Präskripten hilft einen Rückbezug zu derjenigen in Ps 18,1 herzustellen, zumal wenn - wie in Ps 57 - weitere Momente an Gemeinsamkeit wie die Zufluchtsmotivik hinzukommen. Gewisse Berührungen mit Ps 18 finden sich zudem in Ps 61-62 sowie am Ende in Ps 71-72. Dass der Psalter gegenüber den Samuelbüchern neben Gemeinsamkeiten im David-Bild auch andere Akzente setzt, macht ein Vergleich zwischen 2 Sam 22 und Ps 72 evident: Die kriegerischen Momente sind in Ps 72 zurückgedrängt, das Rechtsverhalten und der Einsatz gegenüber den personae miserae betont. Hinzu kommt

42 Vgl. ferner ישע 18,51 (pl); 62,2.3.7 (sg); (Nomen) 18,3.36.47; 62,8.

43 Vgl. פלט 18,3.4.28.36.47; 71,2.3. 
noch, dass 2 Sam 22 (Ps 18) ein retrospektiver, Ps 72 eher ein prospektiver Charakter eignet.

\section{3d Psalm 18 und seine Aufnahme und Bedeutung in Psalm 73-89}

Die Zufluchts-Topik ist in Teilbuch III gering, und dieses enthält mit Ps 86 einen einzigen David-Psalm, der aber kaum signifikante Bezüge zu Ps 18 aufweist. Dies lässt annehmen, dass dieser Psalterteil die von Ps 18 angeschlagene Thematik kaum wachhält. Dem ist insgesamt so, freilich bieten mit Ps 78 und v. a. Ps 89 zwei nicht David zugeschriebene Psalmen Aussagen über ihn, die im Zusammenhang mit Ps 18 zu beachten sind.

Der asaphitische Eröffnungspsalm 73 enthält als einziger dieses Teilbuchs eine חסה-Formulierung $(73,28)$. Zudem prädiziert er wie nachher Ps 78 Gott als „Felsen“ (73,26; 78,35, vgl. noch 89,27). Dafür sind in den AsaphPsalmen allerdings eher „mosaische“ als „,davidische“ Anleihen anzunehmen (vgl. die Belege im Moselied Dtn 32). ${ }^{44}$ Was die Theophanie betrifft, gibt es hinsichtlich der Diktion einige Übereinstimmungen zwischen den entsprechenden Passagen in Ps 18 und Ps 77 (sowie Hab 3). ${ }^{45}$ Die Bezeichnung Davids als JHWHs „Knecht“ im Präskript von Ps 18,1 findet sich ähnlich in Ps 78,70, im davidischen Ps 86 (V. 2.4) und akzentuiert im Schlusspsalm des Teilbuchs (89,4.21.40). Ansonsten sind die David-Aussagen am Ende von Ps 78 anderer Art als in Ps 18. Deutlicher sind die Analogien (und Differenzen) zwischen Ps 18 und dem sich mit dem Bestand des Davidsbundes beschäftigenden Ps 89 am Buchende. Es ist ein im Umfang ähnlicher (kompositer) „Königspsalm“ wie Ps 18, freilich gegenläufiger Prägung: Wird in Ps 18 (2 Sam 22) der Sieg über die Feinde Davids besungen, so enthält Ps 89 zwar einen längeren Lobpreis (V. 2-19), zudem wird auf Gottes Hilfszusage an David referiert (V. 20-38), am Schluss aber wird die Preisgabe des Gesalbten eingeklagt (V. 39-52). Singt David in 2 Sam 22 // Ps 18 am Ende seines Lebens das Lob über Gottes Rettung, so beklagt Ps 89 das Ende des davidischen Königtums. ${ }^{46}$

Fazit: In der Konstellation des Psalters als Buch lässt sich aufgrund der Kontaktstellen eigentlich nur bei Ps 89 eine deutliche Evozierung von 2 Sam 22 // Ps 18 denken - und zwar im Sinne eines Kontrastbildes zwischen der

44 Vgl. Beat Weber, „Der Asaph-Psalter: eine Skizze,“ in »Wie ein Baum, eingepflanzt an Wasserrinnen « (Psalm 1,3): Beiträge zur Poesie und Theologie von Psalmen und Psalter in Wissenschaft und Kirche (von Beat Weber; hrsg. von Torsten Uhlig; ABG 41; Leipzig: Evangelische Verlagsanstalt, 2014), 371-374.

45 Vgl. dazu Beat Weber, Psalm 77 und sein Umfeld: Eine poetologische Studie (BBB 103; Weinheim: Beltz Athenäum, 1994), 215-220.

46 Zur Erwähnung Davids bzw. der Rede vom „Gesalbten“ vgl. 18,1.51 mit 89,4.21.36.39.50.52. 
Bezeugung der Gotteshilfe durch David und der Beklagung des Untergangs des davidischen Königtums.

\section{3e Psalm 18 und seine Aufnahme und Bedeutung in Psalm 90-150}

Zwischen Ps 89 und den folgenden Psalmen liegt die stärkste Zäsur innerhalb des Psalters. Die beiden Teilbücher IV (Ps 90-106) und V (107-150) nehmen wir für unsere Fragestellung zusammen und fragen danach, ob sich - trotz der sich weiter vergrössernden literarischen „Distanz“ - wesentliche (Rück-)Bezüge zu Ps 18 eruieren lassen und - falls ja - in welcher Art und Weise diese erfolgen. Die Zufluchts-Terminologie bzw. die für Ps 18 wichtige Thematik der Bergung bei JHWH hat sich als wesentliches Verbindungsband des davidischköniglichen Danklieds zu weiteren Psalmen, namentlich im ersten חסה Davidpsalter, herausgestellt. Ableitungen der diesbezüglichen Leitwurzel führen im Blick auf den hier zu untersuchenden Buchbereich schwergewichtig zum Eingang von Teilbuch IV (Ps 90-92; 94) und zur letzten DavidpsalmenSammlung (Ps 138-145), dort v. a. zu Ps 140-144 (mit 142 liegt zudem die letzte Überschrift mit Angaben zur vita David vor). ${ }^{47}$ Der Befund bestätigt sich, wenn man die Bezeichnung „Fels“ im Sinne einer Gottesprädikation $(18,3.32 .47$; 92,16; 94,22; 95,1; 144,1) und weitere (Zufluchts-)Begrifflichkeit hinzunimmt. 48 Innerhalb der beiden genannten Psalmencluster stechen Ps 91 (sowie 94) und Ps 144 noch heraus und verdienen einen näheren Augenschein.

Ps 91, der schlechthin als „Zufluchtspsalm“ (teils mit über Ps 18 hinausgehender Begrifflichkeit) gilt, ist aufgrund dieser und der RettungsThematik mit Ps 18 verbunden. ${ }^{49}$ Freilich wird in Ps 91 deutlich, dass die Bergung bei Gott gefährdeter und umkämpfter ist als in Ps 18. Eine für 91,2 zu vermutende Anlehnung an das ,alte,“ Zitat-artig eingeführte Bekenntnis von 18,3 bzw. 2 Sam 22,2-33 ist so erklärbar (vgl. ähnlich, Ps 91 und 94 verklammernd, 94,22). ${ }^{50}$

תפלה למשה :Dsalterteilbuch IV eröffnet „mosaisch“ (vgl. Ps 90,1) איש־האלהים), und unter diesem Referenzhorizont figurieren auch die nachfolgenden, nicht präskribierten Psalmen. Es ist von daher gut denkbar, dass

47 Vgl. zu חסה (18,3.31) 91,4; 141,8; 144,2, ferner noch 118,8-9, zu מחסה (18) 91,2.9; 94,22; 142,6, ferner 104,18.

48 Vgl. משגב 18,3; 94,22; 144,2, מצודה 18,3 91,2; 144,2 - im gleichen Vers auch מגן, vgl. 18,3.31.36. Beachtung verdient auch der Umstand, dass die Formulierung Mann der Gewalttat“ im Psalter nur in Ps 18,49 (// 2 Sam 22,49) und 3mal in Ps 140 (V. 2.5.12) erscheint (im AT darüber hinaus lediglich noch in Spr 3,31; $16,29)$.

49 Zum Retten durch Gott vgl. 91,3.14-15 (u. a. mit פלט - חלץ - חלץ - dand seltenere auch in 140,2).

50 Vgl. auch die Analogie zwischen 18,41 und 94,24 das Vernichten der Feinde (צמת) durch David bzw. JHWH betreffend (dazu in der 140er-Gruppe 143,12). 
allfällige David-Bezüge sich zugleich als Bezüge zu Mose (und den mit ihnen verbundenen Überlieferungen) erweisen. Besonders markant ist diesbezüglich die Prädizierung JHWHs als „Fels“, insbesondere wo sie mit der Bergung verbunden ist (vgl. Dtn 32,37 mit Ps 94,22). Dass die Mose-David-,BBrücke“ im Psalter bereits wesentlich durch Ps 18 (// 2 Sam 22) errichtet wurde, zeigen Parallelitäten zwischen den finalen Stücken 2 Sam 22 (// Ps 18) und Dtn 32,1-43.51 Mit der in Ps 18 gegenüber 2 Sam 22 zusätzlichen Bezeichnung „Knecht JHWHs“ (18,1, vgl. 2 Sam 22,1) ist die Analogie zwischen Mose und David verstärkt (dazu s. o.). Damit ist der „mosaischen Imprägnierung“ von Teilbuch IV, das seinerseits mit David-Bezügen verwoben ist (vgl. die DavidPsalmen 101 und 103), vorgearbeitet. Vergleichbares lässt sich - wenn auch weniger deutlich - im Blick auf die Theophanie-Passagen in den nachfolgenden JHWH-König-Psalmen (Ps 93; 95-99) sagen (vgl. Ps 18,8-16). 52 Denn mit Mose ist nicht nur sein testamentarisches Lied verbunden, sondern auch das Lied nach der Rettung am Meer (Ex 15,1-18), an dessen Ende bekanntlich JHWHs Königtum ausgerufen wird (Ex 15,18, vgl. auch Ps $29,10) .53$

Zum Schluss ist ein vertiefter Blick auf Ps 144 zu werfen. Der vorletzte David-Psalm im Buch hat von allen Psalmen (vor sowie) nach Ps 18 die deutlichsten Anleihen, ja offensichtliche Parallelen zu ihm. ${ }^{54}$ Zwar greift der ,anthologische“ Ps 144 auch auf andere Psalmen (vgl. z. B. 144,3 mit 8,5) zurück, aber Ps 18 ist sein Ausgangs- und Leittext. Das davidisch-königliche Danklied kommt also gegen Ende des Psalters nochmals in neuer Weise zum Erklingen, wie der nachfolgende Vergleich deutlich macht:55

\begin{tabular}{|c|c|c|c|}
\hline $144,1 \mathrm{a}$ & ברוב יהוה צורי & חי־יהוה וברוך צורי & 18,47 \\
\hline $144,1 b$ & המלמד ידי לקרב אצבעותי למלחמה & מלמד ידי למלחמה ונחתה קשת- & 18,35 \\
\hline & & נחושה זרועתי & \\
\hline 4,2 & חסדי ומצודתי משגבבי ומפלטי לי מגני & יהוה סלעי ומצודתי ומפלטי אלי צורי & 18,3 \\
\hline & ובו חסיתי הרודד עמי תחתי & 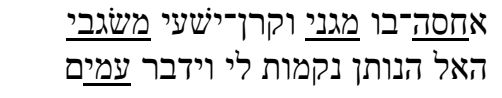 & 18,48 \\
\hline & & תחתי & \\
\hline 4,5 & יהוה הט־שמיך ותרד & ויט שמים וירב וערפל תחת רגליו & 18,10 \\
\hline
\end{tabular}

51 Belege und erste Auswertung bei Markl, Gottes Volk, 253-276.

52 Dazu etwa 18,10 und 97,2 sowie 18,11 und 99,1.

53 Vgl. etwa Ps 99,1 mit Ps 18,8.11 und Ex 15,14, Ps 97,3 mit Dtn 32,22.

54 Dazu Christoph Buysch, Der letzte Davidpsalter: Interpretation, Komposition und Funktion der Psalmengruppe Ps 138-145 (SBB 63; Stuttgart: Katholisches Bibelwerk, 2009), 284: „Die Verbindungen zu Ps 18 sind deutlich, allerdings nie so, dass wortgenau zitiert würde." Ähnlich zuvor Hans-Peter Mathys, Dichter und Beter: Theologen aus spätalttestamentlicher Zeit (OBO 132; Fribourg: Universitätsverlag / Göttingen: Vandenhoeck \& Ruprecht, 1994), 262-266.

55 Vgl. dazu Buysch, Der letzte Davidpsalter, 301-304; Ballhorn, Zum Telos, 277285. Zu Ps 144 vgl. auch Weber, Werkbuch Psalmen II, 361-364. 
214 Weber, „Gelobt sei der HERR, mein Fels ...!“ OTE 29/1 (2016): 195-220

\begin{tabular}{|c|c|c|c|}
\hline $144,5 b$ & גע בהרים ויעשנו & 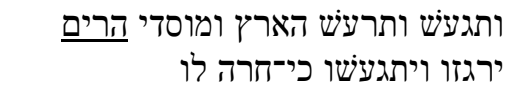 & 18,8 \\
\hline 144,6 & ברוק ברק ותפיצם ששלח חציך ותהמם & ויששלח חציו ויפיצבם וברקים רב ויהמב & 18,15 \\
\hline \multirow[t]{6}{*}{144,7} & ששלח ידיך ממרום פצני והצילני ממים & יששלח ממרום יקחני ימשני ממים רבים & 18,17 \\
\hline & רבים מיד בני נכרך & & \\
\hline & & ממנילני מאיבי עז ומשנאי כי־אמצו & 18,18 \\
\hline & & לשמע אזן ישמעו לי בַני־נכר יכחשו- & $18,45^{56}$ \\
\hline & & לי & \\
\hline & & מאישלטי מאסיבי אף מן־קמי תרוממני & 18,49 \\
\hline \multirow[t]{2}{*}{144,9} & אלהים שיר חדש אשירה לך בנבל & על־־ן אודך בגוים יהוה ולשמך אזמרה & 18,50 \\
\hline & עשור אזמרה־לך & & \\
\hline 144,10 & הבנותן תשרועה למלכים הפוצה את־דוֹ & 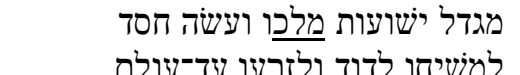 & 18,51 \\
\hline \multirow[t]{4}{*}{144,11} & פצני והצילני מיד בני־נכר אשר פיהם & יצילני מאיבי עז ומשנאי כי־אמצו & 18,18 \\
\hline & דבר־שוא וימינם ימין שקר & ממני & \\
\hline & & לישמע אזן ישמעו לי בני־נכר יכחשוך & $18,45^{57}$ \\
\hline & & 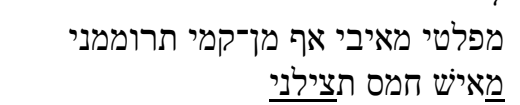 & 18,49 \\
\hline
\end{tabular}

Der Vergleich macht deutlich, dass sich die Rezeption von Ps 18 auf 144,1-11 (mit Refrain-artigen Versen 7-8 // 10-11) beschränkt.58 Umgekehrt greift Ps 144 aus Ps 18 Wendungen mit Gottesprädikationen, Zuversichts- und Rettungsbekenntnissen zu Beginn (V. 3) und v. a. im Schlussteil auf (V. 4551), ferner auf die Theophanie und ihre positiven Folgen (V. 8.10.15.17-18). Ausgespart bleiben Aussagen über Recht und Frömmigkeit in 18,21-31.

Bereits der Anfang in 144,1 evoziert Ps 18 als Bezugstext. Dabei fällt auf, dass die von Gott gelehrte Kompetenz der Kriegsführung entkonkretisiert wird. In 144,2 wird die von Gott gewährte Position des Königs nicht wie in Ps 18 gegenüber den (Fremd-)Völkern, sondern gegenüber dem eigenen Volk herausgestellt (was an innere Konflikte und Verwerfungen denken lässt). Nachdem 144,3-4 ohne Bezüge zu Ps 18 sind, greifen 144,5-7 neuerdings auf das königlich-davidische Danklied zurück - und zwar auf die Theophanie und ihr Ausgang. Anders als in Ps 18 wird in Ps 144 Gottes Kommen aber nicht bezeugt, sondern erbeten (Imperative). Folgt 144,6 recht deutlich 18,15, so hat 144,7 wohl nicht nur 18,17, sondern auch 18,18 und 18,45(-46) im Blick. Auch hier wird der aus der Theophanie sich ergebende Rettungsakt nicht bezeugt,

56 Die Wendung Söhne der Fremde“ erscheint auch im nachfolgenden V. 46.

57 Die Wendung Söhne der Fremde“ erscheint auch im nachfolgenden V. 46.

58 Sie fehlt im deutlich abgehobenen Schlusspassus V. 12-15 mit „Wir“-Gruppe und finaler, doppelter Seligpreisung. 
sondern erbeten. Die Feinde werden (anders als in Ps 18) durchgehend pluralisch ausgedrückt. Die „Söhne der Fremde“ könnten in nachexilischer Zeit (vgl. Neh 9,2) Grössen im Innern sein (wie der nachfolgende Vers 144,8 annehmen lässt). Anders als in Ps 18 erscheinen diese in Ps 144 als eigentliche Gegner. In 144,9-11 wird letztmals auf Ps 18 zurückgegriffen (die Refrainartige Aufnahme wurde bereits oben bedacht). Möglicherweise ist mit der Ankündigung des Singens eines „,neuen Lieds“59 hier implizit auf das ,alte,“ nämlich Ps 18, verwiesen. Der Verweis auf David sowie die Intonierung dieses neuen Lieds (des Anfangs?) in 144,10ab60 könnten dies bestätigen. Mit den „Königen“ dürften auf dem Hintergrund von 18,51 („David und sein Same“) die Davididen im Blick sein. ${ }^{61}$ Die auffällige Umkehrung (davidische) Könige $\Rightarrow$ David in 144,10 rückt einen neuen David in den Fokus und lässt messianische Obertöne anklingen. Wenn er kommt und Rettung bringt, ist das Singen einen neuen Lieds angezeigt, wie einst bei der Erst-Rettung das Urlied (Ex 15,1-18) angestimmt wurde (vgl. 144,9 mit Ex 15,1).

Fazit: In der (wohl späteren) hinteren Hälfte des Psalters kommt am Anfang (Teilbuch IV) und zum Schluss (Teilbuch V, vor dem Halleluja-Finale Ps 146-150) das alte königlich-davidische Danklied (Ps 18) zu neuer Geltung. Werden zu Beginn (Ps 91; 94) daraus v. a. Zufluchts- und Zuversichtsaussagen in notvoller Zeit geschöpft, so bietet Ps 144 innerhalb der armentheologisch geprägten letzten Psalmengruppe Ps 138-145 ein Beispiel dafür, wie in gewandelter Zeit auf autoritativ gewordene Psalmen zurückgegriffen, diese neu gehört und angewendet werden. Dabei fällt gegenüber Ps 18 neuerlich eine (schon früher, bei anderen Psalmen notierte) „Entmilitarisierung“62 auf; sie ist auch dadurch gegeben, dass die „Feinde“ nun nicht mehr Fremdvölkern sind, sondern in der eigenen Gesellschaft lauern. Zu ihren Waffen gehören Trug und Hinterlist. Auf dem Hintergrund des im Danklied Ps 18 bezeugten Gottesheils für den Messias und sein Volk wird in gewandelter Zeit mit Ps 144 ein solches neuerlich erbeten. Gottes neues Eingreifen wird auch ein neues königlichdavidisches Danklied hervorrufen.

59 Zur Begrifflichkeit und seinen Verstehenshorizonten Beat Weber, „Ein neues Lied,““ BN 142 (2009): 39-46.

60 Vorgeschlagen wird gegenüber MT eine Änderung der Kolometrie mit den Bikola 10ab, 10c11a und 11bc (und den Strophen 9a-10b und 10c-11c).

61 Vgl. auch die von der Wurzel ישע abgeleiteten Nomina für das Gottesheil in 144,10 und 18,51.

62 Ballhorn, Zum Telos, 283, spricht von „Entpolitisierung (Abschwächung der Davidgestalt, Tilgung der Dynastiezusage)“ und dass König David zur Privatperson geworden sei, die dem Beter als Vorbild diene. Eine derart starke „Entroyalisierung“ Davids scheint mir jedoch nicht vorzuliegen, wobei das Verständnis der Aussagen von Ps 144,10-11 zugegebenermassen nicht leicht zu erheben ist. 
216 Weber, „Gelobt sei der HeRR, mein Fels ...!“ OTE 29/1 (2016): 195-220

\section{SCHLUSSÜBERLEGUNGEN}

Ausgehend von einem kanontheologischen Horizont und einem rezeptionsästhetischen Ansatz unter Betonung der primären (quasi-narrativen) Leserichtung des Psalters (lectio continua) ${ }^{63}$ hatte der vorliegende Beitrag Ps 18 unter einem zweifachen Lesegefälle (Buch- und Kanonkontext) im Blick. Basierend auf jüngst publizierten Darlegungen zum Überschriftssystem der biographischen Hinweise zur vita David ${ }^{64}$ wurde die Sekundarität des Psalters gegenüber den Samuelbüchern herausgestellt und seine Rückbezüglichkeit auf diese betont. Beides wird angezeigt durch die biographischen Hinweise zum Leben Davids in den ersten beiden David-Psaltern und in Verbindung mit der Doppelgestalt des davidisch-königlichen Danklieds in 2 Sam 22 und Ps 18. Entsprechend ist die kanonhermeneutische Bedeutung dieses Psalms kaum zu überschätzen. Um die Herausarbeitung seiner buchtheologischen Signifikanz innerhalb des Psalters ging es im Hauptteil dieser Studie. Wurde in einer gesonderten Studie das Psalter-Vorfeld von Ps 18 in den Blick genommen (Ps 1-17), ${ }^{65}$ so ging es hier um die Erarbeitung und Konturierung seines Nachfelds innerhalb des Buchs (Ps 19-150). Bei beiden Lesestadien spielt der Hintergrund von 2 Sam 22 eine Rolle, doch mit dem „Einholen“ des königlich-davidischen Danklieds in Gestalt von Ps 18 in den Psalter rückt dieser im Nachfeld in den Vordergrund - freilich ohne dass das Wissen darum, dass Ps 18 in 2 Sam 22 seine Hintergrund-fundierung hat, aus dem Bewusstsein getilgt wird.

Das Bedenken der (wiederholten, memorierenden) Leseabfolge der Psalmen im Nachfeld von Ps 18 unter der Fragestellung, ob, inwiefern und in welcher (modifizierten) Weise dieser Psalm durch sprachliche Signalisatoren nachklingt und in der Rezeption erkennbar wird, ${ }^{66}$ erfolgte etappenweise unter Berücksichtigung anerkannter Merkmale der Buchgliederung. Als wesentliche „Verbinder“, die Rückbezüge zu Ps 18 (und 2 Sam 22) wachhalten bzw. neu

63 Ballhorn, Zum Telos, 25, weist darauf hin, dass die Buchgestalt als Rolle die lineare Wahrnehmung des Textes vom Anfang zum Ende aufgrund des Umstandes, dass man nur über das Abrollen des Textes von vorn nach hinten gelangt, noch verstärkt.

64 Vgl. Weber, ,An dem Tag.“

65 Vgl. v. a. Weber, „Das königlich-davidische Danklied,“ ferner auch Weber, „HERR, wie viele sind geworden,“ 240-249; Botha und Weber, „Killing Them Softly,“ 136-138.

66 Auch wenn die sequentielle (zeitliche) Textabfolge im Rezeptionsvorgang als primär einzustufen ist, wird Mehrfachlesung und damit Meditierung und Memorierung durch den Psaltereingang (vgl. Ps 1, insbesondere 1,2) angezielt. Sie führt nicht nur zu einer „Vergleichzeitigung“ bzw. „Verräumlichung“ der Texte (innerhalb derer chiastische Anlagen überhaupt erst erkennbar werden), sondern auch zu einer vertieften „Abschöpfung“ von Sinnpotenzen. Auf Ps 18 gemünzt: Wiederholte „Durchgänge“ durch den Psalter erleichtern bzw. vermehren die Wahrnehmung von Textrelationen nachfolgender Psalmen mit Ps 18. 
aufrufen, erwiesen sich Gattungsmerkmale (Königspsalmen), Präskript- und andere David-Bezüge und v. a. Begriffe, Motive und Traditionen. Am prägnantesten ist das Motivcluster der ,Zuflucht bei JHWH“ (mit der Leitwurzel חסה ,Fels“-Prädikationen und anderem mehr). Dieses findet sich durch den Psalter hindurch, wenn auch in unterschiedlicher Dichte und Ausprägung. ${ }^{67}$ Ein besonderer Schwerpunkt liegt, beginnend mit dem Erstbeleg in Ps 2,12, im ersten Davidpsalter und darin in Ps 18 - mit seinem ,vorgelagerten“ Pendant 2 Sam 22 (vgl. auch den חסה-Erstbeleg im Moselied: Dtn 32,37). ${ }^{68}$ Als zweites neben dem Wortfeld der Bergung bei Gott (und mit ihm oft verbunden) ist dasjenige der Rettung (vor Feinden) und des Heils bei JHWH zu nennen. Mit der Zufluchtsmotivik einher geht ein frömmigkeitlicher Aspekt. Jerome Creach formuliert es so: „Central to the hasa hasâ field is the idea that Yahweh is the only reliable source of protection and that an attitude of dependence upon Yahweh is the most basic element of piety." 69 Dieser Frömmigkeitsaspekt ist bereits in 2 Sam 22 // Ps 18 greifbar, wird aber im Nachfeld von Ps 18 innerhalb des Psalters verstärkt. Im Fortgang durch den Psalter tritt zu dieser Art von weisheitlicher (Tora-)Spiritualität mit ihrer gebetstheologischen Vertiefung eine Theologisierung und „Entmilitarisierung“, verbunden mit Veränderungen im David-Bild. So wird die Kampf- und Siegfähigkeit über den militärischen Bereich hinaus ausgeweitet und teils von David auf JHWH verschoben. Zugleich tritt neben dem Messias sein bzw. Gottes Volk verstärkt in den Blick. In Gestalt der den Psalter im Sinne einer oratio et meditatio spiritualis nachvollziehenden Gemeinschaft ist das Gottesvolk gleichsam copräsent. In Ps 2 wird die Machtverleihung an den messianischen Zionskönig durch den Himmelskönig betont, und Ps 18 bietet ein beglaubigendes DavidZeugnis der dort ergangenen Zusage. Am Ende des zweiten Psalms wird dann in der Gestalt einer Seligpreisung die Zufluchtsmotivik im Psalter eröffnet (Ps 2,12). Am Buchende in Ps 144, vor dem abschliessenden Halleluja-Finale (Ps 146-150), kommen wesentliche Aussagen von Ps 18 in modifizierter Weise nochmals zur Sprache. Der eröffnende Lobpreis prädiziert neuerlich JHWH als „Fels (der Zuflucht)“. Am Ende steht wie in Ps 2 eine (bzw. zwei) Seligpreisung(en); die dort offene Adressierung ist nun aber inhaltlich gefüllt: das Gottesvolk. Damit wird das David-Bild „vergrundsätzlicht“ und kollektiviert. Ps 145, der allerletzte David-Psalm, geht insofern noch einen Schritt weiter, als David seine royale Würde gleichsam ablegt und als

67 Dazu Creach, Yahweh as Refuge. Die „Fels““-Prädikationen (סלע, erscheinen dabei nur im psalmischen Nachfeld, nicht aber im Vorfeld von Ps 18.

68 Die Zufluchtsbegrifflichkeit prägt - von 2 Sam 22 her - bereits das Vorfeld (Ps 2 17) und bestimmt - von Ps 18 (und 2 Sam 22) her - dann auch das Nachfeld. Vgl. dazu Weber, „Das königlich-davidische Danklied“, 190-201, und die Ausführungen in dieser Studie.

69 Creach, Yahweh as Refuge, 37. 
Lobpreisender mit und für die Gemeinschaft „deiner Getreuen“ (V. 10) die Königsherrschaft JHWHs besingt. ${ }^{70}$

Die Bedeutung des königlich-davidischen Danklieds (2 Sam 22 // Ps 18) innerhalb des biblischen Kanons zeigt sich allein schon durch seine Doppelpräsenz, eingebettet in zwei unterschiedliche Schriften. Zwar hat Ps 18 innerhalb des Psalters nicht die 2 Sam 22 eigene, hervorgehobene Stellung innerhalb der Samuelbücher, die durch das poetische Genre (im narrativen Umfeld) und die Positionierung am Buchschluss zustande kommt. Die Gewichtung ist aber auch im Psalter gegeben, wenn auch in anderer Weise realisiert. Dort ist dieser David-Psalm zwar nicht ganz am Anfang, aber doch im Anfangsbereich des Buches platziert. Seine Wirkungen strahlen in der Folge ins Buch hinein aus, werden teils transformiert und sind in der Rezeption mit Hilfe von Repetierung und Memorierung (vgl. Ps 1,2) erkennbar. Seinen letzten, starken Akzent hat Ps 18 in Ps 144, wo er gegen das Buchende hin durchaus analog zu 2 Sam 22 innerhalb der Samuelbücher! - in modifizierter Weise neu sein Wort ausrichtet.

\section{BIBLIOGRAPHIE}

Ballhorn, Egbert. Zum Telos des Psalters: Der Textzusammenhang des Vierten und Fünften Psalmenbuches (Ps 90-150). Bonner Biblische Beiträge 138. Berlin: Philo, 2004.

Barbiero, Gianni. Das erste Psalmenbuch als Einheit: Eine synchrone Analyse von Psalm 1-41. Österreichische Biblische Studien 16. Frankfurt a. M.: Peter Lang, 1999.

Botha, Phil J. und Beat Weber. ,»Killing Them Softly with this Song ...« The Literary Structure of Psalm 3 and Its Psalmic and Davidic Contexts." Seiten 102-146 in »Wie ein Baum, eingepflanzt an Wasserrinnen " (Psalm 1,3): Beiträge zur Poesie und Theologie von Psalmen und Psalter in Wissenschaft und Kirche. Von Beat Weber. Herausgegeben von Torsten Uhlig. Arbeiten zur Bibel und ihrer Geschichte 41. Leipzig: Evangelische Verlagsanstalt, 2014.

Buysch, Christoph. Der letzte Davidpsalter: Interpretation, Komposition und Funktion der Psalmengruppe Ps 138-145. Stuttgarter Biblische Beiträge 63. Stuttgart: Katholisches Bibelwerk, 2009.

Creach, Jerome F. D. Yahweh as Refuge and the Editing of the Hebrew Psalter. Journal for the Study of the Old Testament: Supplement Series 217. Sheffield: Sheffield Academic Press, 1996.

Hossfeld, Frank Lothar und Till Magnus Steiner. „Problems and Prospects in Psalter Studies." Seiten 240-258 in Jewish and Christian Approaches to the Psalms:

70 Vgl. Beat Weber, „Makarismus und Eulogie im Psalter: Buch- und kanontheologische Erwägungen," in »Wie ein Baum, eingepflanzt an Wasserrinnen " (Psalm 1,3): Beiträge zur Poesie und Theologie von Psalmen und Psalter in Wissenschaft und Kirche (von Beat Weber; hrsg. von Torsten Uhlig; ABG 41; Leipzig: Evangelische Verlagsanstalt, 2014), 451-453. 
Weber, „Gelobt sei der HERR, mein Fels ...!“ OTE 29/1 (2016): 195-220

Conflict and Convergence. Herausgegeben von Susan Gillingham. Oxford: Oxford University Press, 2013.

Johnson, Vivian L. David in Distress: His Portrait Through the Historical Psalms. Library of Hebrew Bible/Old Testament Studies 505. New York: T \& T Clark, 2009.

Kleer, Martin. »Der liebliche Sänger der Psalmen Israels«: Untersuchungen zu David als Dichter und Beter der Psalmen. Bonner Biblische Beiträge 103. Bodenheim: Philo, 1996.

Markl, Dominik. Gottes Volk im Deuteronomium. Beihefte zur Zeitschrift für Altorientalische und Biblische Rechtsgeschichte 18. Wiesbaden: Harrassowitz, 2012.

Mathys, Hans-Peter. Dichter und Beter: Theologen aus spätalttestamentlicher Zeit. Orbis Biblicus et Orientalis 132. Fribourg: Universitätsverlag / Göttingen: Vandenhoeck \& Ruprecht, 1994.

Stone, Timothy J. The Compilational History of the Megilloth: Canon, Contoured Intertextuality and Meaning in the Writings. Forschungen zum Alten Testament II/59. Tübingen: Mohr Siebeck, 2013.

Sumpter, Philip. „The Coherence of Psalms 15-24.“ Biblica 94 (2013): 186-209.

Van der Lugt, Pieter. Cantos and Strophes in Biblical Hebrew Poetry: With Special Reference of the First Book of the Psalter. Oudtestamentische Studiën 53. Leiden: Brill, 2006.

Weber, Beat. Psalm 77 und sein Umfeld: Eine poetologische Studie. Bonner Biblische Beiträge 103. Weinheim: Beltz Athenäum, 1995.

Werkbuch Psalmen II. Die Psalmen 73 bis 150. Stuttgart: Kohlhammer, 2003.

. „Der Beitrag von Psalm 1 zu einer ,Theologie der Schrift. ““ Jahrbuch für evangelikale Theologie 20 (2006): 83-113.

. „HERR, wie viele sind geworden meine Bedränger ...' (Ps 3,2a). Psalm 1-3 als Ouvertüre des Psalters unter besonderer Berücksichtigung von Psalm 3 und seinem Präskript." Seiten 231-251 in Der Bibelkanon in der Bibelauslegung: Methodenreflexionen und Beispielexegesen. Herausgegeben von Egbert Ballhorn und Georg Steins. Stuttgart: Kohlhammer, 2007. . ,„Ein neues Lied.“" Biblische Notizen 142 (2009): 39-46.

. Werkbuch Psalmen III. Theologie und Spiritualität des Psalters und seiner Psalmen. Stuttgart: Kohlhammer, 2010.

. „,An dem Tag, als JHWH ihn rettete aus der Hand aller seiner Feinde und aus der Hand Sauls' (Ps 18,1): Erwägungen zur Anordnung der biographischen Angaben zu David im Psalter.“ Vetus Testamentum 64 (2014): 284-304.

. „Die Psalmen: Persönliche Akzente zu Psalmen und Psalter sowie deren Erforschung“. Seiten 18-29 in »Wie ein Baum, eingepflanzt an Wasserrinnen « (Psalm 1,3): Beiträge zur Poesie und Theologie von Psalmen und Psalter in Wissenschaft und Kirche. Von Beat Weber. Herausgegeben von Torsten Uhlig. Arbeiten zur Bibel und ihrer Geschichte 41. Leipzig: Evangelische Verlagsanstalt, 2014.

. „Von der Psaltergenese zur Psaltertheologie: Der nächste Schritt der Psalterexegese?! Einige grundsätzliche Überlegungen zum Psalter als Buch und Kanonteil.“ Seiten 64-76 in »Wie ein Baum, eingepflanzt an Wasserrinnen " (Psalm 1,3): Beiträge zur Poesie und Theologie von Psalmen und Psalter in 
Wissenschaft und Kirche. Von Beat Weber. Herausgegeben von Torsten Uhlig. Arbeiten zur Bibel und ihrer Geschichte 41. Leipzig: Evangelische Verlagsanstalt, 2014 (Erstveröffentlichung: 2010). . „Psalm 1 als Tor zur Tora Jhwhs: Wie Ps 1 (und Ps 2) den Psalter an den Pentateuch anschliesst." Seiten 332-352 in »Wie ein Baum, eingepflanzt an Wasserrinnen " (Psalm 1,3): Beiträge zur Poesie und Theologie von Psalmen und Psalter in Wissenschaft und Kirche. Von Beat Weber. Herausgegeben von Torsten Uhlig. Arbeiten zur Bibel und ihrer Geschichte 41. Leipzig: Evangelische Verlagsanstalt, 2014 (Erstveröffentlichung: 2007).

. „Der Asaph-Psalter: eine Skizze.“ Seiten 363-391 in »Wie ein Baum, eingepflanzt an Wasserrinnen «(Psalm 1,3): Beiträge zur Poesie und Theologie von Psalmen und Psalter in Wissenschaft und Kirche. Von Beat Weber. Herausgegeben von Torsten Uhlig. Arbeiten zur Bibel und ihrer Geschichte 41. Leipzig: Evangelische Verlagsanstalt, 2014 (Erstveröffentlichung: 2001).

. „Psalm 78 als »Mitte« des Psalters? - ein Versuch.“ Seiten 392-411 in »Wie ein Baum, eingepflanzt an Wasserrinnen "(Psalm 1,3): Beiträge zur Poesie und Theologie von Psalmen und Psalter in Wissenschaft und Kirche. Von Beat Weber. Herausgegeben von Torsten Uhlig. Arbeiten zur Bibel und ihrer Geschichte 41. Leipzig: Evangelische Verlagsanstalt, 2014 (Erstveröffentlichung: 2007).

- „Makarismus und Eulogie im Psalter, Buch- und kanontheologische Erwägungen." Seiten 431-457 in »Wie ein Baum, eingepflanzt an Wasserrinnen " (Psalm 1,3): Beiträge zur Poesie und Theologie von Psalmen und Psalter in Wissenschaft und Kirche. Von Beat Weber. Herausgegeben von Torsten Uhlig. Arbeiten zur Bibel und ihrer Geschichte 41. Leipzig: Evangelische Verlagsanstalt, 2014 (Erstveröffentlichung: 2008).

„Die Psalmen als Wort $z u$ Gott und als Wort von Gott: Über den Sondercharakter des Psalmenbuchs innerhalb der Heiligen Schrift." Seiten 458-462 in »Wie ein Baum, eingepflanzt an Wasserrinnen " (Psalm 1,3): Beiträge zur Poesie und Theologie von Psalmen und Psalter in Wissenschaft und Kirche. Von Beat Weber. Herausgegeben von Torsten Uhlig. Arbeiten zur Bibel und ihrer Geschichte 41. Leipzig: Evangelische Verlagsanstalt, 2014 (Erstveröffentlichung: 2002).

. „Das königlich-davidische Danklied 2 Samuel 22 / Psalm 18 im Kontext von Psalm 1-18: Eine (proto)kanonische Lesung vom Ende der Samuelbücher her zum Anfangsbereich des Psalters hin.“ Seiten 187-204 in „Canterò in eterno le misericordie del Signore" (Sal 89,2): FS Gianni Barbiero. Herausgegeben von Stefan M. Attard und Marco Pavan. Analecta Biblica 3. Rom: Gregorian \& Biblical Press, 2015.

„BiblioPss 1990+: Bibliography of Psalms and the Psalter since 1990 (Update II.2016).“ Zitiert 1 März 2016. Online: https://www .academia.edu 15910732/BiblioPss1990_Bibliography_of_Psalms_and_the_Psalter_since_199 0_Update_III.2016_.

Beat Weber, Lecturer in Old Testament at Theologisches Seminar Bienenberg (Liestal), Switzerland \& Research Associate of the Department of Ancient Languages and Cultures, University of Pretoria, South Africa. Email: weberlehnherr@sunrise.ch. 